\title{
Putative function and physiological relevance of the mitochondrial uncoupling protein-3: Involvement in fatty acid metabolism?
}

Citation for published version (APA):

Schrauwen, P., Hoeks, J., \& Hesselink, M. K. (2006). Putative function and physiological relevance of the mitochondrial uncoupling protein-3: Involvement in fatty acid metabolism? Progress in Lipid Research, 45(1), 17-41. https://doi.org/10.1016/j.plipres.2005.11.001

Document status and date:

Published: 01/01/2006

DOI:

10.1016/j.plipres.2005.11.001

Document Version:

Publisher's PDF, also known as Version of record

\section{Document license:}

Taverne

Please check the document version of this publication:

- A submitted manuscript is the version of the article upon submission and before peer-review. There can be important differences between the submitted version and the official published version of record.

People interested in the research are advised to contact the author for the final version of the publication, or visit the DOI to the publisher's website.

- The final author version and the galley proof are versions of the publication after peer review.

- The final published version features the final layout of the paper including the volume, issue and page numbers.

Link to publication

\footnotetext{
General rights rights.

- You may freely distribute the URL identifying the publication in the public portal. please follow below link for the End User Agreement:

www.umlib.nl/taverne-license

Take down policy

If you believe that this document breaches copyright please contact us at:

repository@maastrichtuniversity.nl

providing details and we will investigate your claim.
}

Copyright and moral rights for the publications made accessible in the public portal are retained by the authors and/or other copyright owners and it is a condition of accessing publications that users recognise and abide by the legal requirements associated with these

- Users may download and print one copy of any publication from the public portal for the purpose of private study or research.

- You may not further distribute the material or use it for any profit-making activity or commercial gain

If the publication is distributed under the terms of Article $25 \mathrm{fa}$ of the Dutch Copyright Act, indicated by the "Taverne" license above, 


\title{
Putative function and physiological relevance of the mitochondrial uncoupling protein-3: Involvement in fatty acid metabolism?
}

\author{
Patrick Schrauwen ${ }^{\mathrm{a}, *}$, Joris Hoeks ${ }^{\mathrm{a}}$, Matthijs K.C. Hesselink ${ }^{\mathrm{b}}$ \\ a Nutrition and Toxicology Research Institute Maastricht (NUTRIM), Department of Human Biology, Maastricht University, \\ P.O. Box 616, 6200 MD, Maastricht, The Netherlands \\ ${ }^{\mathrm{b}}$ Nutrition and Toxicology Research Institute Maastricht (NUTRIM), Department of Movement Sciences, Maastricht University, \\ P.O. Box 616, 6200 MD, Maastricht, The Netherlands
}

\begin{abstract}
The discovery of the human homologue of the thermogenic protein UCP1, named uncoupling protein 3 (UCP3), boosted research on the role of this skeletal muscle protein in energy metabolism and body weight regulation. Nowadays, 9 years after its discovery emerging data indicate that the primary physiological role of UCP3 may be the mitochondrial handling of fatty acids rather than regulating energy expenditure via thermogenesis. UCP3 has been proposed to export fatty acid anions or fatty acid peroxides away from the matrix-side of the mitochondrial inner membrane to prevent their deleterious accumulation. In this way, UCP3 could protect mitochondria against lipid-induced oxidative mitochondrial damage, a function especially important under conditions of high fatty acid supply to skeletal muscle mitochondria. Such function may be clinically relevant in the development of type 2 diabetes mellitus, a condition characterized by muscular fat accumulation, mitochondrial damage and low levels of UCP3.
\end{abstract}

(C) 2005 Elsevier Ltd. All rights reserved.

Keywords Uncoupling protein; Reactive oxygen species; Fatty acid transport; Mitochondria; Diabetes

\section{Contents}

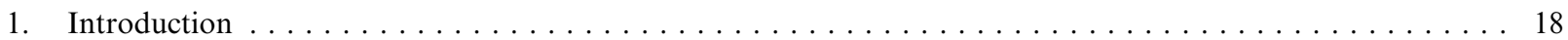

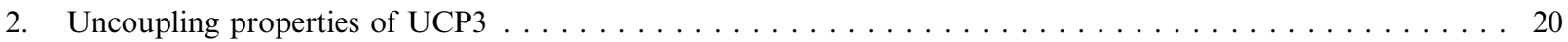

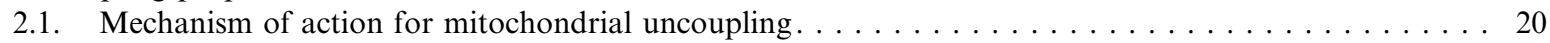

Abbreviations: ACS, acyl-CoA synthase; BAT, brown adipose tissue; CPT, carnitine palmitoyltransferase; CRE, cyclic AMP response element; DNP, 2,4-dinitrophenol; FCCP, carbonylcyanide $p$-trifluoromethoxyphenylhydrazone (an uncoupling reagent); KO, knock-out (animals); MEF, myocyte enhancher factor; MtDNA, mitochondrial DNA; MTE, mitochondrial (acyl-CoA) thioesterase; PPAR, peroxisome proliferator activated receptor; RMR, resting metabolic rate; ROS, reactive oxygen species; RXR, retinoid X receptor; TRE, thyroid-responsive element; $\mathrm{T}_{3}$, triiodothyronine; UCP, uncoupling protein; WAT, white adipose tissue.

Corresponding author. Tel.: +31 43 3881502; fax: +31 433670976.

E-mail address: p.schrauwen@hb.unimaas.nl (P. Schrauwen). 


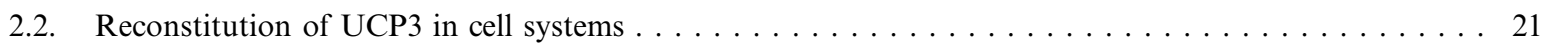

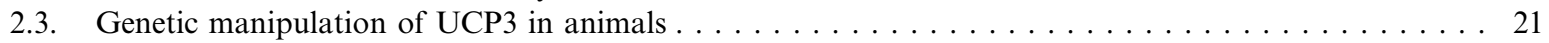

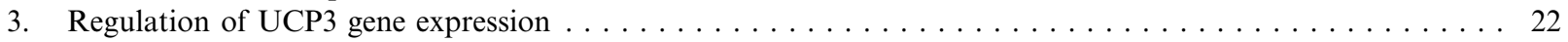

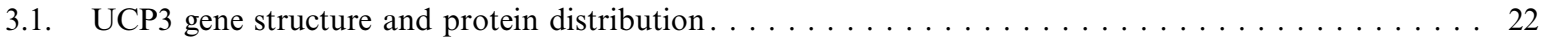

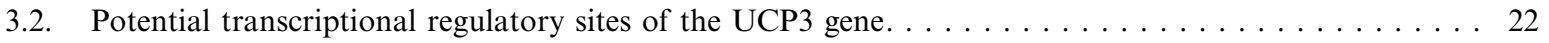

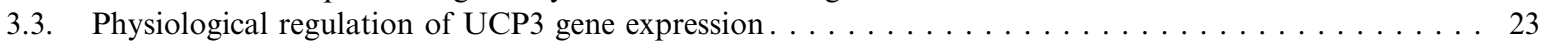

3.3.1. Thyroid hormone and UCP3 gene expression $\ldots \ldots \ldots \ldots \ldots \ldots \ldots \ldots \ldots \ldots \ldots \ldots$

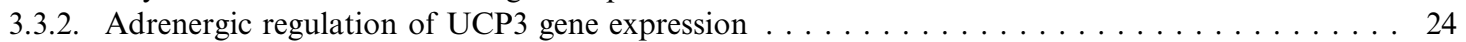

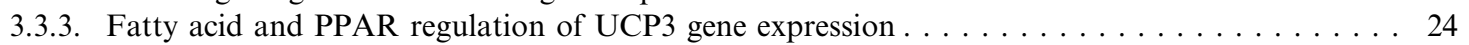

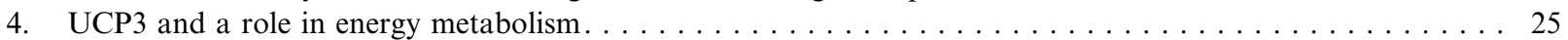

4.1. UCP3 and energy metabolism as evidenced by linkage and association studies . . . . . . . . 25

4.2. Investigations of skeletal muscle UCP3 mRNA and protein content in relation to energy

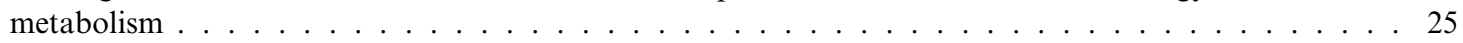

4.3. Energy metabolism in mice over- and underexpressing UCP3 . . . . . . . . . . . . . . . . . 26

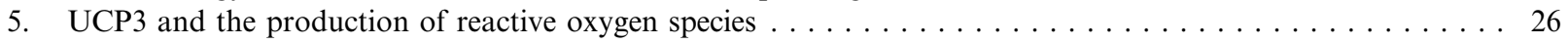

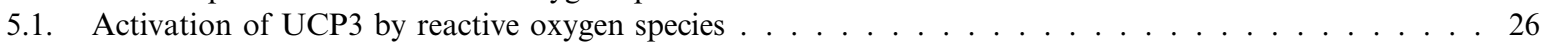

5.2. Inhibition of reactive oxygen species production by UCP3 . . . . . . . . . . . . . . . . . 27

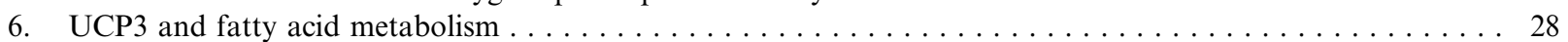

6.1. Physiological conditions showing a positive relationship between UCP3 and fatty acid metabolism . . 28

6.2. Physiological conditions showing a negative relationship between UCP3 and fatty acid metabolism . . 29

6.3. UCP3 as a mitochondrial exporter of fatty acids when fatty acid oxidation predominates . . . . . . . 29

6.4. UCP3 as a mitochondrial exporter of non-metabolizable fatty acids $\ldots \ldots \ldots \ldots \ldots \ldots \ldots \ldots$

6.5. $\mathrm{UCP} 3$ as a mitochondrial exporter of lipid peroxides $\ldots \ldots \ldots \ldots \ldots \ldots \ldots \ldots \ldots \ldots \ldots \ldots \ldots \ldots$

7. Physiological relevance of $\mathrm{UCP} 3$ : a role in lipotoxicity? $\ldots \ldots \ldots \ldots \ldots \ldots \ldots \ldots \ldots \ldots \ldots \ldots \ldots$

7.1. A unifying function for UCP3: protection against lipid-induced oxidative damage $\ldots \ldots \ldots \ldots \ldots 33$

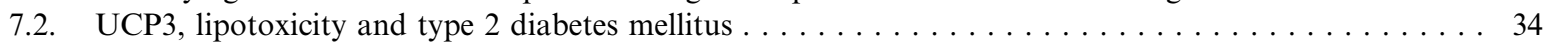

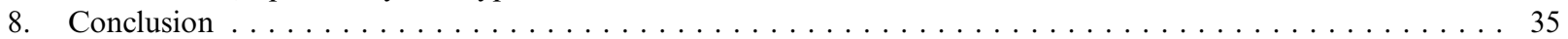

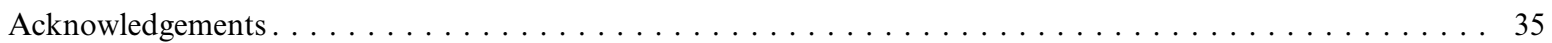

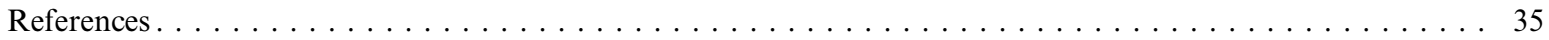

\section{Introduction}

Mitochondrial energy production is essential for life, as most cellular processes require energy that is released from the hydrolysis of adenosine triphosphate (ATP). To maintain ATP levels, mitochondria are equipped with a so-called electron transport chain, a series of protein complexes located in the inner mitochondrial membrane, in which potential energy derived from the breakdown of nutrients is converted into ATP. In processes like glycolysis, $\beta$-oxidation and the TCA cycle, the carbon-rich nutrients fatty acids, carbohydrates and proteins are stepwise degraded to carbon dioxide and water together with the formation of the reduced coenzymes $\mathrm{NADH}$ and $\mathrm{FADH}_{2}$. Inside mitochondria the reduced coenzymes are oxidized and the liberated electrons are transferred through the protein complexes (I-IV) of the electron transport chain towards molecular oxygen, which is subsequently reduced to water. According to the chemiosmotic theory defined by Mitchell [1], the electron transfer leads to a proton transfer across the inner mitochondrial membrane, resulting in an electrochemical gradient. If this proton gradient is high enough, protons flow back to the mitochondrial matrix via the $\mathrm{F}_{0}-\mathrm{F}_{1}$-ATPase complex, thereby releasing the energy needed to phosphorylate adenosine diphosphate (ADP) and generate ATP (oxidative phosphorylation) (Fig. 1). Theoretically, protons can only flow back via the ATPase complex, resulting in a tight and efficient coupling between substrate degradation and ATP formation. Indeed, chemical uncouplers like 2,4-dinitrophenol impair mitochondrial ATP production and are detrimental to life.

In tightly coupled mitochondria, inhibition of the ATPase complex, either chemically or by depleting its substrate ADP, would result in a profound increase in the proton gradient across the inner mitochondrial membrane. The increased proton gradient prevents reduction of additional $\mathrm{NADH}$ or $\mathrm{FADH}_{2}$. As a resultant, mitochondrial respiration is abolished and mitochondrial oxygen consumption should be negligible. The 


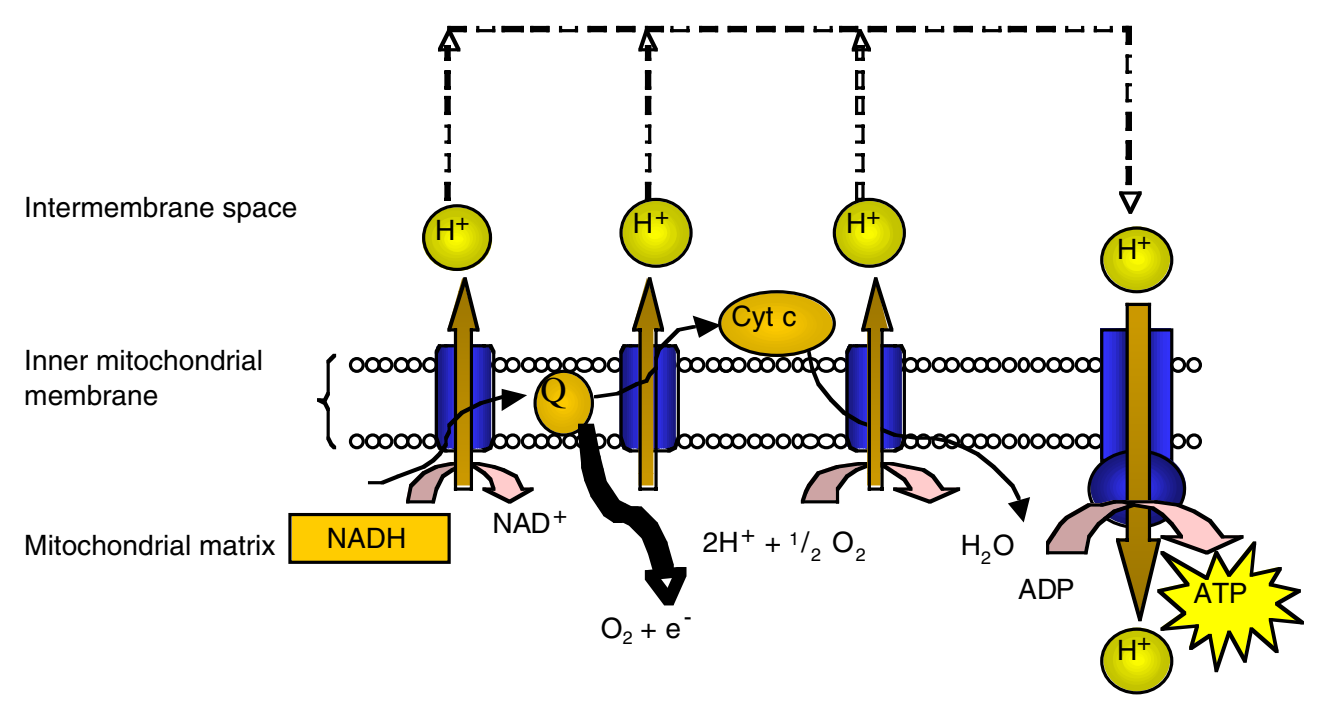

Fig. 1. The electron transport chain: In mitochondria, NADH and $\mathrm{FADH}_{2}$, reducing equivalents derived from the degradation of food substrates donate electrons to oxygen, the final electron acceptor, and the energy released during this process is used to pump protons from the mitochondrial matrix to the intermembrane space. As a result, an electrochemical gradient is created across the inner mitochondrial membrane. The exported protons flow back into the mitochondrial matrix through the $\mathrm{F}_{0}-\mathrm{F}_{1}$-ATPase and the energy generated is used to synthesize ATP from ADP and inorganic phosphate (Pi).

latter, however, is not observed in experimental settings: although profoundly blunted, isolated mitochondria incubated in the presence of substrate but depleted of ADP still consume oxygen, suggesting, that under these conditions the proton gradient can be lowered via routes other than the ATPase complex. The residual oxygen consumption in the absence of ADP, referred to as state 4 respiration (see Fig. 2), indicates that mitochondrial respiration can be partially 'uncoupled' from ATP production, thereby reducing the efficiency of ATP generation by mitochondria.

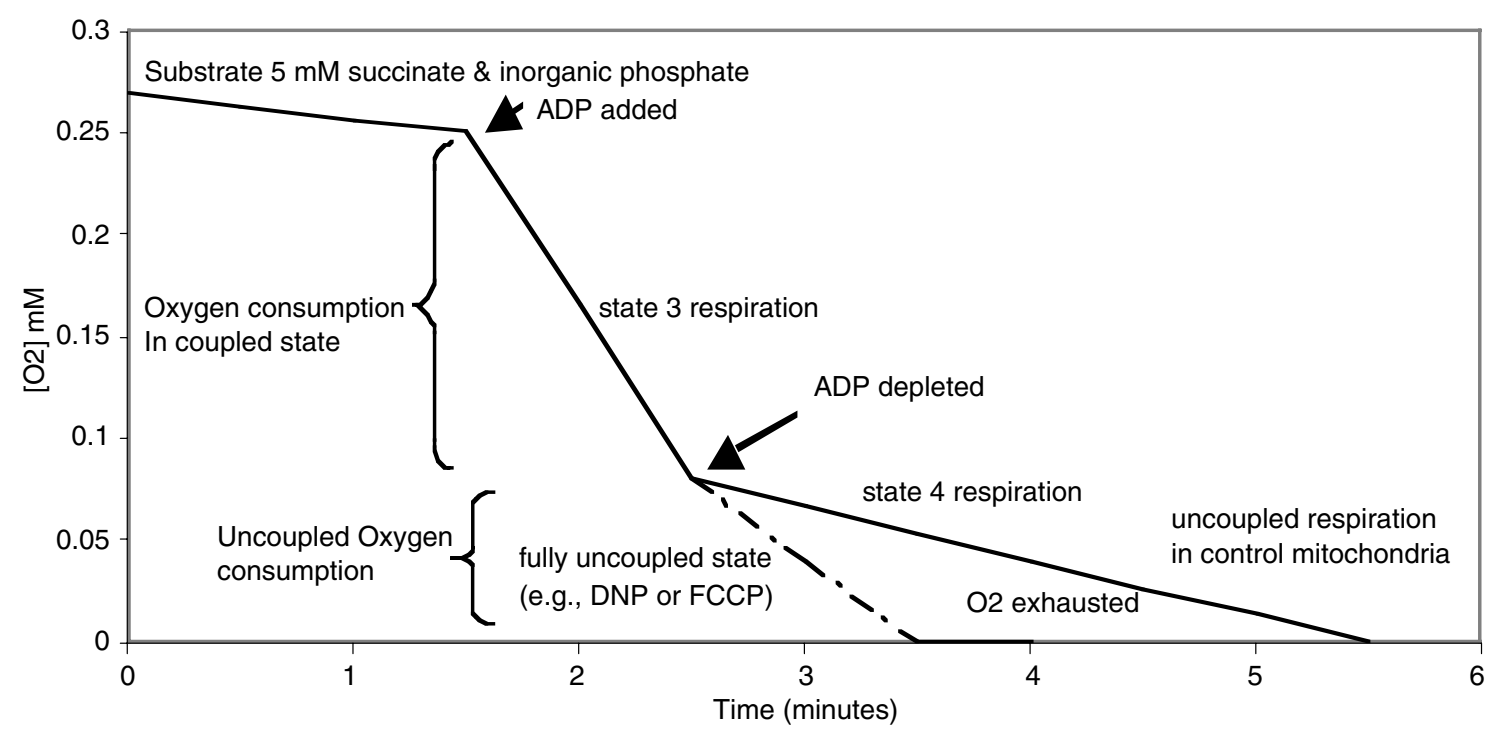

Fig. 2. State 3 and state 4 respiration in isolated mitochondria: oxygen consumption in the presence of substrate (succinate), inorganic phosphate and ADP is referred to as state 3 respiration. Under state 3 conditions, oxygen consumption is coupled to phosphorylation of ADP to ATP. On depletion of ADP (and thus without ATP synthesis), mitochondria continue respiration at a much lower rate, referred to as state 4 respiration. In this case, respiration is uncoupled from ATP synthesis and the proton gradient is lowered by proton leak. 
If mitochondrial energy production is so essential to life, one would assume that mitochondrial uncoupling only exists as an apparent inevitable by-product of the mitochondrial system. Indeed, a small proportion of mitochondrial oxygen consumption is due to uncontrolled leakage of electrons from the electron transport chain from reduced oxygen to superoxide and hydrogen peroxide [2]. Remarkably, however, a major part of mitochondrial uncoupling is not simply due to inefficiency of the system, but is highly regulated by the activation of destined mitochondrial uncoupling proteins. This conclusion is mainly drawn from research conducted on the thermogenic capacity of brown adipose tissue (BAT). This tissue plays a major role in the regulation of cold-induced and diet-induced thermogenesis via the production of heat [3]. Already in 1967 it was observed that respiration in mitochondria isolated from brown adipose tissue was coupled loosely to ATP production [4], and it was demonstrated that this uncoupled respiration was activated by fatty acids and inhibited by GTP, GDP, ATP and ADP [5,6]. Several years later, a $32 \mathrm{kDa}$ protein was identified as the binding site for these nucleotides, and from then onward, this protein would be referred to as the first discovered uncoupling protein (UCP, later renamed as UCP1) [7]. Continuing research on this UCP1 for almost 30 years have shown that this UCP1 is essential for cold-induced thermogenesis and UCP1 ablated mice are incapable of maintaining body temperature when exposed to cold [8].

Although the presence of UCP1 provides an explanation for the observed mitochondrial uncoupling in mitochondria isolated from brown adipose tissue, UCP1 protein expression appears to be restricted to brown adipose tissue mitochondria. Nevertheless, mitochondrial uncoupling is a phenomenon that can be observed in mitochondria isolated from a variety of tissues. For example, it has been calculated that in vivo proton leak in liver and skeletal muscle mitochondria may account for $\sim 20 \%$ of the basal oxygen consumption [9]. The protein(s) responsible for the proton leak in these tissues had however not been identified. In 1997, however, two UCP1 homologues were cloned with putative uncoupling activity: UCP2 [10] and UCP3 [11].

In contrast to UCP2, which is ubiquitously expressed [10], the expression of UCP3 is limited to skeletal muscle, heart and brown adipose tissue [11], tissues with an important role in energy and substrate metabolism. Extensive research on the regulation and the putative functions of these novel uncoupling proteins has resulted in a vast amount of papers in the last 9 years. Notwithstanding the overwhelming number of studies published, there appears to be no consensus yet on the primary function and the physiological implications of UCP2 and UCP3. UCP2 among others has been implicated in the regulation of insulin secretion, neuroprotection and defense against ROS production. For more details on UCP2, however, the reader is referred to several excellent reviews on the putative function of UCP2 [12-16]. In the present review, we will discuss the literature available on the regulation and putative function of the skeletal muscle UCP3.

\section{Uncoupling properties of UCP3}

\subsection{Mechanism of action for mitochondrial uncoupling}

After many years of research, the mechanism by which the original mitochondrial uncoupling protein UCP1 is able to induce uncoupling is still under debate. Mitochondrial uncoupling is achieved by a lowering of the proton gradient, which can either be achieved by allowing protons to flow from the intermembrane space into the matrix, or by the export of negatively charged anions from the matrix into the intermembrane space. So far, the proposed mechanisms by which UCP1 uncouples can be summarized by two models. In the first model, proposed by Klingenberg and Huang [17], UCP1 actually transports protons, and fatty acids facilitate this process by donating protons to proton-buffering amino acids in the channel within the UCP. In the second model, sometimes referred to as the Skulachev/Garlid/Jezek hypothesis [18-20], UCP is involved in the outward translocation of fatty acid anions from the matrix. In the latter model, neutral fatty acids flip-flop over the inner mitochondrial membrane and donate a proton to the matrix. The resulting fatty acid anions, which are not able to flip-flop back, are transported by UCP and pick up a proton in the intermembrane space. In both models, fatty acids are essential for stimulating uncoupling activity, which is in accordance with the general consensus that at least in experimental conditions, fatty acids stimulate, and nucleotides inhibit UCP1 induced mitochondrial uncoupling [5,21]. Therefore, regulation by fatty acids and/or nucleotides seems to be an important criterion in determining whether the novel uncoupling protein UCP3 possesses uncoupling activity. 


\subsection{Reconstitution of UCP3 in cell systems}

On its discovery it was, based on its homology with uncoupling protein-1, assumed that UCP3 also possesses mitochondrial uncoupling activity. In the search for evidence for uncoupling activity, most studies reconstituted the UCP3 protein into liposomes or yeast cells and measured proton fluxes, oxygen consumption and/or membrane potential. Jabůrek et al. [22] expressed human UCP3 in Escherichia coli and subsequently reconstituted the protein into liposomes. Their results implicated that UCP3 is capable of catalyzing an electrophoretic proton flux (qualitatively) similar to UCP1, and that this UCP3-mediated proton flux is dependent on fatty acids [22]. Purine nucleotides, known to be potent inhibitors of UCP1, also inhibited proton transport mediated by UCP3 in this proteoliposome model, although the effect was lower in comparison with UCP1 [22]. In another study, human uncoupling protein 3 was expressed in yeast cells, resulting in an increase in the overall rate of oxygen consumption and a decrease in mitochondrial membrane potential [23]. Zhang et al. [24] also used a UCP3-transfected yeast expression system and showed that state 4 respiration (i.e., respiration in absence of exogenous ADP), expressed as percentage of maximal respiratory capacity (FCCP-stimulated respiration), was significantly increased. GDP, a potent inhibitor of UCP1, did not reverse the uncoupling activity of UCP3.

Although these results implicate that UCP3 can possess uncoupling properties, subsequent studies showed that the incorporation of UCP3 in yeast cells results largely in a deranged and non-physiological state, thereby allowing an uncontrolled proton transport $[25,26]$, which could explain the lack of GDP-inhibition on UCP3 induced uncoupling. In agreement, Harper et al. [27] revealed that the concentration of UCP3, at which yeast mitochondria display obvious uncoupling, was 7-fold higher than physiological concentrations present in rodent skeletal muscle, whereas with physiological concentrations only very little uncoupling was detected. Transfection of UCP3 in L6 myocytes also resulted in uncoupling of respiration, which was unaffected by purine nucleotides and fatty acids, again suggesting that UCP3 overexpression results in uncontrolled uncoupling due to improper folding of the protein or incomplete incorporation into the inner membrane, rather than representing a physiological phenomenon [28]. The lack of inhibition of uncoupling activity by purine nucleotides (and sometimes also the lack of activation by fatty acids), prerequisites for uncoupling action of UCP1, are nowadays especially considered to be criteria for regulated uncoupling activity of UCP3.

\subsection{Genetic manipulation of UCP3 in animals}

The question of UCP3 being a true uncoupler has also been addressed in genetically modified mice overand underexpressing UCP3. Mice overexpressing human uncoupling protein-3, were shown to be hyperphagic but lean, indicating that UCP3 is capable of increasing energy expenditure in vivo [29]. Oxygen consumption measurements in skeletal muscle mitochondria of these mice revealed an increase in state 4 respiration, a decrease in state 3 respiration and a $12 \%$ decrease in mitochondrial membrane potential, indicating mitochondrial uncoupling [29]. Similar to the reconstitution studies described above, the main criticism to these findings was that overexpression of UCP3 might have resulted in non-physiological, uncontrolled uncoupling. Thus, Cadenas et al. [30] studied whether the uncoupling observed in mice overexpressing UCP3 was native (i.e., uncoupling that can be inhibited by GDP and/or activated by fatty acids) or a non-native artefact (i.e., uncoupling that cannot be manipulated). They found that GDP had no effect on proton conductance in UCP3 overexpressing mice. Also, they failed to detect a difference between UCP3 overexpressing mice and their wild-type littermates with respect to uncoupling activated by fatty acids, leading to the conclusion that the uncoupling effect measured in UCP3 transgenic mice is unregulated and an overexpressing artefact [30].

The criticism of non-physiological expression of UCP3 cannot be applied to studies that examined the effect of UCP3 ablation on mitochondrial uncoupling. Unfortunately, such studies have not yet revealed a uniform answer towards the question whether UCP3 activity is necessary for mitochondrial uncoupling. Thus, VidalPuig et al. [31] reported a significant decrease in state 4 respiration, but unaffected state 3 in mice lacking UCP3, indicating increased mitochondrial coupling [31]. In addition, Gong et al. [32] and Bezaire et al. [33] showed that skeletal muscle mitochondria of UCP3 ablated mice displayed an increased protonmotive force, but no difference in state 4 respiration. In a more physiological approach, Cline et al. [34] examined in vivo mitochondrial uncoupling using 31P-nuclear magnetic resonance (NMR) in mice lacking UCP3. Mice lacking 
UCP3 had increased rates of ATP synthesis with unaltered TCA cycle fluxes, a result that was interpreted as increased coupling between substrate oxidation and ATP production. In contrast, Cadenas et al. [30] reported that the basal proton conductance in skeletal muscle mitochondria of UCP3-KO animals was similar to that of their wild-type littermates.

Taken together, although overexpression of UCP3 does seem to result in mitochondrial uncoupling, this uncoupling activity appears to be insensitive to GDP as is hence considered an experimental artefact. On the other hand, data obtained in systems lacking UCP3 have not revealed uniform results. Therefore, there is no conclusive evidence that UCP3 can act as a true uncoupling protein comparable to UCP1. However, this does not exclude that UCP3 can function as a transporter of protons or fatty acid anions, thereby lowering the proton gradient, albeit that such action might require different activators when compared to the classical, thermogenic uncoupling protein UCP1.

\section{Regulation of UCP3 gene expression}

\subsection{UCP3 gene structure and protein distribution}

UCP3 was discovered through screening of a human skeletal muscle cDNA library for sequences homologous to UCP1. With this technique, Boss et al. [11] showed that two RNA transcripts for UCP3 exist, which are predicted to encode a long $\left(\mathrm{UCP}_{\mathrm{L}} ; 312\right.$ amino acids) and a short (UCP3 $3_{\mathrm{S}} ; 275$ amino acids) isoform of the UCP3 protein. Solanes et al. [35] showed that the human UCP3 gene consists of 7 exons spread over $\sim 8.5 \mathrm{~kb}$ and is located on chromosome 11 (11q13), adjacent to the $\mathrm{UCP} 2$ gene [35]. $\mathrm{UCP} 3_{\mathrm{L}}$ and $\mathrm{UCP} 3_{\mathrm{S}}$ are derived from alternative splicing at the end of exon 6 and a polyadenylation signal present in intron 6 [35]. The long and short isoforms only differ by a 37 amino acid residue on the $\mathrm{C}$ terminus and both variants showed a $57 \%$ and 73\% similarity in amino acid sequence in comparison with UCP1 and UCP2, respectively [11].

The translated sequence from the coding cDNA for $\mathrm{UCP} 3_{\mathrm{L}}$ predicts 6 transmembrane domains and a purine nucleotide binding domain, similarly to UCP1 and UCP2. The protein generated by the short UCP3 transcript would theoretically lack the last transmembrane domain and the purine nucleotide binding domain [11]. In human skeletal muscle, both UCP3 transcripts seem to be equally expressed [35], whereas in rodents only the long UCP3 mRNA isoform is present [36]. Northern blot analysis on the expression pattern of UCP3 in rats revealed that UCP3 mRNA is expressed abundantly in skeletal muscle and BAT but was also present in cardiac muscle and white adipose tissue (WAT), although at much at lower levels [37]. At the protein level, UCP3 was detected in skeletal muscle, BAT and cardiac muscle [38,39]. Comparison of cardiac and skeletal muscle revealed that UCP3 protein content was highest in glycolytic muscle (white gastrocnemius), 2-3-fold lower in oxidative muscle (soleus) and 10-fold lower in cardiac muscle (Fig. 3) [39]. Also in humans UCP3 protein content was highest in glycolytic, type 2 muscle fibers and lowest in oxidative, type 1 muscle fibers [40].

\subsection{Potential transcriptional regulatory sites of the UCP3 gene}

Analysis of the $5^{\prime}$-flanking, promoter region of the human UCP3 gene revealed several potential sequences that can act as binding sites for regulatory transcription factors. Among these, recognition motifs for musclespecific regulatory factors such as an E-box, a MEF2 binding site and a CCAC-box were identified [41,42]. Both MEF2 and the CCAC-box motif are important for transcriptional regulation of muscle-specific genes [43], whereas the E-box is a binding site for the myogenic factor $\mathrm{MyoD}$, a factor that is required for substantial promoter activity of the UCP3 gene [44]. These regulatory factors help to understand the muscle-specific expression pattern of UCP3.

Next to regulatory sites allowing muscle-specific expression of UCP3, the promoter region of UCP3 also contains retinoic acid- and PPAR-responsive elements $[41,42,44,45]$. The presence of these PPAR-responsive elements is in line with numerous physiological observations showing that high levels of plasma free fatty acids, which are PPAR ligands, induce the expression of UCP3 [46-49]. In cell-transfection studies, Solanes et al. [44] indeed showed that UCP3 gene transcription was initiated by PPAR $\alpha$ and PPAR $\delta$ activation, but not PPAR $\gamma[44]$. 


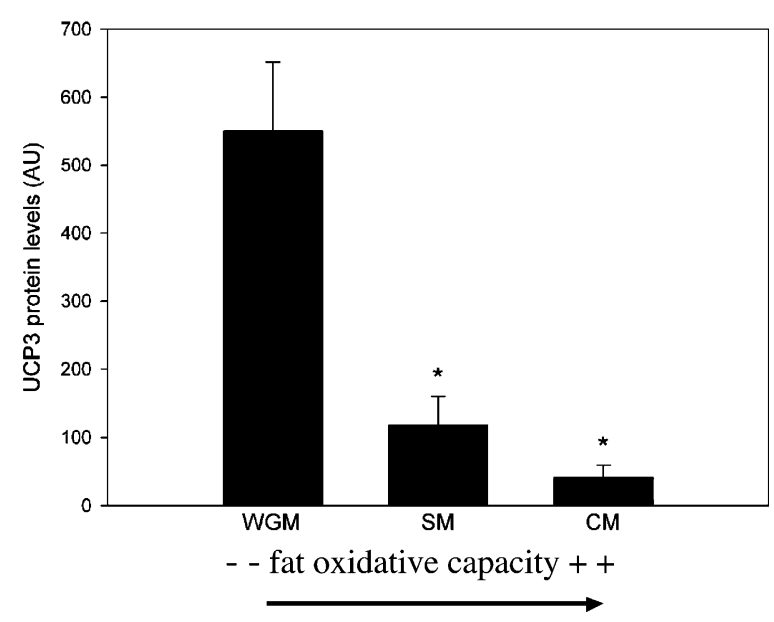

Fig. 3. UCP3 protein content in rat white gastrocnemius (WGM), soleus (SM) and cardiac (CM) muscle. Fat oxidative capacity is highest in cardiac muscle and lowest in white gastrocnemius, indicating an inverse relationship between UCP3 and fat oxidative capacity. Data taken from [39].

The promotor of the UCP3 gene also contains several potential motifs responsive to thyroid hormone $[41,42,50]$. Recent work by Solanes et al. [50] revealed that the thyroid-responsive element [TRE] coincided with the reported site responsible for responsiveness to PPAR and retinoids, indicating that this site acts as a multihormonal responsive element. In addition, the initiation of UCP3 gene transcription by retinoids and thyroid hormone also requires MyoD [50]. Finally, the UCP3 promoter region contains a cAMP response-like element [41], suggesting that UCP3 gene transcription may be activated by physiological stimuli that involve cAMP as a second messenger, such as adrenergic stimulation.

\subsection{Physiological regulation of UCP3 gene expression}

Based on the binding sites in the promotor of UCP3, the anticipated physiological stimuli that regulate UCP3 gene expression include thyroid hormone, adrenergic stimulation, PPAR activity and/or fatty acid levels. Many rodent and human studies have been addressing the physiological regulation of UCP3, as will be discussed below.

\subsubsection{Thyroid hormone and UCP3 gene expression}

Numerous publications reported that thyroid hormone status or thyroid hormone treatment is capable of upregulating UCP3 mRNA and protein levels [51-57]. Lanni et al. [58] showed a $\sim 5$-fold decrease in UCP3 mRNA levels in hypothyroid rats, while hyperthyroid rats displayed a $\sim 5$-fold increase in UCP3 expression, as compared to euthyroid rats. State 3 and state 4 respiration increased according to thyroid hormone status (i.e., hypothyroid $<$ euthyroid $<$ hyperthyroid), and state 4 respiration correlated with UCP3 mRNA levels [58]. De Lange et al. [55] observed a high similarity in the time course of increased skeletal muscle UCP3 expression, the decrease in mitochondrial respiratory efficiency and the increase in resting metabolic rate when hypothyroid rats were given a single injection of triiodothyronine $\left(\mathrm{T}_{3}\right)$. Maximal UCP3 expression (12-fold over basal) was reached at $65 \mathrm{~h}$ after $\mathrm{T}_{3}$ injection and at this time-point, resting metabolic rate was increased by $45 \%$, state 4 respiration by $40 \%$ and membrane potential decreased by $8 \%$, indicative of mitochondrial uncoupling [55].

Using a NMR approach to estimate mitochondrial uncoupling (defined as the rate of TCA flux over ATP synthesis), a decrease in mitochondrial coupling of approximately $60 \%$ was found upon 10 days of $\mathrm{T}_{3}$ treatment, which correlated well with changes in UCP3 mRNA and protein levels [59]. The same technique was applied in humans treated with $\mathrm{T}_{3}$ for three days and a $\sim 70 \%$ increase in muscle TCA flux, with unchanged rate of ATP synthesis was found, indicating increased mitochondrial uncoupling [60]. Unfortunately, the level of UCP3 was not determined in this study. 
In contradiction to these results, Jekabsons et al. [57] reported that 6 days of $T_{3}$ treatment increased both gastrocnemius UCP3 mRNA levels and resting metabolic rate. However, mitochondrial state 4 respiration rates were unaffected by the treatment nor did they correlate with resting metabolic rate [57]. In addition, Gong et al. [32] reported that UCP3 null mice showed the same increase in resting oxygen consumption during 4 days of T3 treatment as wild-type mice, indicating that UCP3 is not necessary for the thyroid-induced thermogenesis.

Taken together, although thyroid hormone can affect UCP3 mRNA expression and protein content, it is not evident that such an increase in UCP3 affects mitochondrial uncoupling or thermogenesis. In that respect, it is important to note that the effect of thyroid hormone on UCP3 gene expression might be indirectly mediated by changes in plasma free fatty acids, since thyroid hormone is well known to induce lipolysis [52].

\subsubsection{Adrenergic regulation of UCP3 gene expression}

Given that the UCP3 gene promoter contains cAMP responsive elements, induction of UCP3 gene expression by serial activation of $\beta$-adrenergic receptor-linked adenylate cyclase, cAMP-dependent protein kinase A, and CRE binding protein, which binds directly to the UCP3 promoter region, is anticipated. Indeed, Nagase et al. [61] observed induction of UCP3 mRNA expression by adding adrenaline or $\beta 2$-adrenergic agonists to L6 myotubes, an effect that could be abolished by $\beta 2$-adrenergic antagonists. In rodents, most studies focused on the effect of $\beta 3$-adrenergic stimulation on UCP3 expression, but with conflicting results [62-64]. In that respect, it is important to note that skeletal muscle is believed to lack the $\beta 3$-adrenergic receptor subtype, suggesting that potential effects of $\beta 3$-adrenergic stimulation on UCP3 expression are indirect, probably via changes in plasma free fatty acids levels due to stimulation of lipolysis. Indeed, Nakamura et al. [64] observed a $\beta 3$-stimulation of UCP3 gene expression, accompanied by increased plasma free fatty acid levels, whereas Yoshitomi et al. [63] found a $\beta 3$-induced downregulation of UCP3 together with decreased circulating free fatty acids.

To unravel the effects of $\beta$-adrenergic stimulation on UCP3 mRNA expression from fatty acid effects, we examined the effect of a 3-h infusion of dobutamine (a $\beta 1$-agonist), salbutamol (a $\beta 2$-agonist) as well as salbutamol plus acipimox (a nicotinic-acid analogue blocking lipolysis) on UCP3 mRNA expression in healthy, lean human subjects [65]. We found no change in skeletal muscle UCP3 mRNA expression upon $\beta 1$ - or $\beta 2$-adrenergic stimulation, but a significant decrease in UCP3 mRNA expression in the salbutamol plus acipimox condition, in which plasma fatty acid levels were markedly reduced.

Together these results indicate that $\beta$-adrenergic stimulation has, if anything, only modest effects on UCP3 mRNA expression, most likely mediated by $\beta$-adrenergic induced changes in plasma fatty acid levels.

\subsubsection{Fatty acid and PPAR regulation of UCP3 gene expression}

Soon after the discovery of UCP3, one of the most contrasting findings - with respect to a putative role of UCP3 in energy metabolism - was that caloric restriction for 5 days resulted in a $\sim 2-3$-fold increase in UCP3 mRNA levels in lean and obese humans [48]. These data were confirmed in rodents, where it was shown UCP3 mRNA was induced 5.6-fold in rat tibialis anterior muscle after a 48 - $\mathrm{h}$ fast, and that $24 \mathrm{~h}$ fasting induced a 3.5-fold increase in UCP3 mRNA in mice soleus muscle without affecting basal heat production in vitro [66]. Weigle et al. [49] were the first to establish that fasting-induced increases in plasma fatty acids were responsible for the increase in UCP3 mRNA: the induction of UCP3 upon fasting could be mimicked by the acute elevation of fatty acids levels via infusion of Intralipid together with heparin, whereas other physiological fastinginduced responses (a decrease in leptin and an increase in corticosterone levels) had no effect on UCP3 mRNA. The effects of acute elevation of plasma fatty acid levels on UCP3 mRNA induction have been confirmed in humans [47]. In addition, refeeding resulting in normalization of plasma fatty acid levels is paralleled by a return of UCP3 mRNA to control values [67]. The importance of fatty acids in the regulation of UCP3 is further underscored by the observation that in mice UCP3 mRNA is induced during postnatal development, but only when mice were weaned on a diet rich in fatty acids [68]. To this evidence adds a long list of physiological conditions such as high-fat feeding [49,68-75] and acute exercise [76-80] all characterized by increased plasma fatty acid levels with concomitant increase in the mRNA expression of UCP3.

The induction of UCP3 by fatty acids is likely to be mediated by PPAR activity, as the UCP3 promotor contains PPAR responsive elements. It is well recognized that fatty acids are natural ligands of PPARs and 
the latter regulate transcription of genes involved in energy and substrate metabolism. Indeed, upregulation of UCP3 mRNA by selective PPAR agonists has been demonstrated in cultured muscle cells $[44,81,82]$. In addition, ligands for RXR which heterodimerises with PPAR, also induce UCP3 mRNA expression $[44,81,82]$. Also in vivo studies showed that UCP3 mRNA can be induced by PPAR agonists in rodents although the results are less straight forward [83-85]. So far, no human data have been published on the effect of PPAR agonists on UCP3, however, we recently found that 8 weeks of rosiglitazone treatment increased UCP3 protein content by $\sim 25 \%$ in skeletal muscle of human diabetic patients (P. Schrauwen, M. Mensink, G. Schaart, E. Moonen-Kornips, J-P. Sels, E.E. Blaak, A.P. Russell, M.K.C. Hesselink, unpublished observation).

\section{UCP3 and a role in energy metabolism}

Eight years after its discovery, the physiological function of UCP3 is still under debate. Although UCP3 has been implicated in a large number of distinct physiological functions, consistent research lines over these years have focused on potential roles for UCP3 in energy metabolism, fatty acid metabolism, and the production of reactive oxygen species. In this and following sections, the possibility of UCP3 being involved in any of these functions will be discussed and placed into the context of the earlier mentioned findings.

\subsection{UCP3 and energy metabolism as evidenced by linkage and association studies}

Based on its homology to UCP1 it was initially anticipated that UCP3 would fulfill a role similar to UCP1 in skeletal muscle, i.e., inducing thermogenesis. As humans lack brown adipose tissue (normally only present shortly after birth), the mechanism by which we induce adaptive thermogenesis (an increase in energy expenditure in response to stimuli like cold, diet or adrenergic stimulation) is still unknown, but it is likely that skeletal muscle plays a pivotal role in adaptive thermogenesis. Therefore, shortly after the discovery of UCP3 in skeletal muscle most research focused on a potential role for this protein in the regulation of energy metabolism in humans.

Following the discovery of a novel gene, genetic studies are often performed to indicate possible relationships between the gene and its proposed function. To this end, geneticists use linkage and association studies to examine whether genetic variation in the gene of interest is associated with a certain phenotype. In the case of UCP3, genetic studies conducted shortly after its discovery found that markers in the vicinity of the UCP2 and UCP3 gene (which are only $7 \mathrm{~kb}$ apart) were very strongly linked $(p<0.0001)$ to resting metabolic rate (RMR) [86]. In an early association study, polymorphisms in the UCP2 and UCP3 gene were associated with sleeping metabolic rate and $24 \mathrm{~h}$ energy expenditure in Pima Indians, as measured in a respiration chamber [87]. The same polymorphisms were also found to be associated with $24 \mathrm{~h}$ energy expenditure in a Danish population [88], as well as with exercise efficiency [89].

A polymorphism in exon 3 of the UCP3 gene was related to resting metabolic rate, both before and after a period of overfeeding, but not with overfeeding-induced changes in resting metabolic rate [90], and a polymorphism in exon 5 was associated with resting metabolic rate in African American women, but not in caucasian [91]. However, in contrast to these positive associations, several studies reporting a lack of association between polymorphisms in the UCP2/UCP3 gene and energy metabolism have been published [92-94]. Many studies have also investigated the association between polymorphism in the UCP3 gene and body weight regulation as a resultant of energy metabolism, but no consistent conclusion can be drawn from these investigations, with both a substantial number of studies showing positive associations between UCP3 and body weight and an equal number of studies showing no association at all (reviewed in [16]). It should of course be realized that, especially in humans, body weight regulation is complex and not only dependent on energy metabolism.

\subsection{Investigations of skeletal muscle UCP3 $\mathrm{mRNA}$ and protein content in relation to energy metabolism}

In 1998, we observed that the level of mRNA expression of UCP3 in skeletal muscle of Pima Indians correlated positively with sleeping metabolic rate (which accounts for $\sim 60 \%$ of total energy expenditure in humans) [95]. In addition, we and others observed that UCP3 mRNA and protein content was reduced after weight reduction, 
which is known to diminish resting metabolic rate [96,97]. Also cold exposure, which is associated with increased thermogenesis, has been associated with increases in UCP3 mRNA and protein content. Acute cold exposure in mice resulted in a 3 -fold increase in UCP3 protein content, accompanied by a pronounced lowering of mitochondrial membrane potential and dissipation of energy as heat [98]. In humans exposed to mild cold for $60 \mathrm{~h}$, we showed that UCP3 protein content was not changed (yet), but did relate to sleeping metabolic rate and $24 \mathrm{~h}$ energy expenditure [99]. In the same study, however, UCP3 mRNA expression was down regulated upon cold exposure, disproving a relation between cold-induced thermogenesis and UCP3. The latter is further substantiated by the notion that in mice lacking UCP1 cold-induced non-shivering thermogenesis is completely absent, suggesting that UCP1 can completely account for cold-induced thermogenesis [100].

Several groups also investigated the relationship between UCP3 and energy metabolism in relation to endurance exercise and training. Endurance trained athletes were found to be characterized by significantly lower levels of UCP3 mRNA expression, which were negatively correlated with aerobic capacity (maximal oxygen consumption: $\mathrm{VO}_{2, \max }$ ) and mechanical energy efficiency [101] and with the slow component of $\mathrm{VO}_{2}$ kinetics (also an indication of energy efficiency) [102]. Also longitudinal studies show that, in humans, UCP3 is rapidly reduced by endurance training [103,104], although these studies did not examine a relationship with energy metabolism. In contrast, most, but not all [105], training studies performed in rodents have observed an upregulation of UCP3 after endurance training [76,106-108]. Part of this controversy may be explained by the fact that in rodent studies, UCP3 has been determined shortly after the last bout of exercise. In that context, both in humans [74,78,80,109,110], and in rodents [76,77,79,111] acute exercise has been shown to upregulate UCP3 mRNA expression, an effect that has been attributed to increased plasma fatty acid levels [80].

Taken together these, and other studies, report associations between UCP3 and energy metabolism (see also Section 3.3.1 thyroid hormone and UCP3 gene expression). However, only after the creation of transgenic mice over- and underexpressing UCP3 it could directly be tested if UCP3 affects energy metabolism.

\subsection{Energy metabolism in mice over- and underexpressing UCP3}

In 2000 the first report on mice overexpressing UCP3 was published, showing that these mice were hyperphagic but lean, suggesting an UCP3-induced increase in resting metabolic rate [29]. However, as mentioned above, these results were later questioned by the fact that the overexpression of UCP3 might have resulted in non-physiological uncoupling due to improper insertion of the protein in the mitochondrial membranes. In addition, results obtained in mice lacking UCP3 were not supportive of a role of UCP3 in energy metabolism. Although mitochondria of these mice tended to be more tightly coupled [31,32], these mice had no apparent phenotype, i.e., they were not obese and had normal metabolic rates. In addition, mice lacking UCP3 showed normal responses to exercise, cold exposure and thyroid hormone [31,32]. In addition, mice lacking both UCP1 and UCP3 could phenotypically not be distinguished from single UCP1 knock-out mice, illustrating that UCP3 does not compensate for the uncoupling action of UCP1 [32].

In summary, although there is evidence for an association between UCP3 and energy metabolism, the general consensus nowadays is that UCP3 is not a major regulator of skeletal muscle thermogenesis and/or body weight. The presence of UCP3 in skeletal muscle is not a prerequisite for proper body weight regulation and, as discussed previously, there is also no firm evidence that UCP3 functions as a true uncoupler. At best, UCP3 may contribute marginally to the energy requirements of skeletal muscle due to a small uncoupling effect for yet undefined physiological reasons. It is important to note however that the data obtained since the discovery of UCP3 have indicated that the process of mitochondrial uncoupling per se does have the potential to contribute to body weight regulation, as for example the artificial uncoupling observed in mice overexpressing UCP3 is accompanied by a lean phenotype [29].

\section{UCP3 and the production of reactive oxygen species}

\subsection{Activation of $\mathrm{UCP} 3$ by reactive oxygen species}

As mentioned previously, UCP3 does not mediate regulated mitochondrial uncoupling, i.e., cannot be inhibited by nucleotides and/or activated by fatty acids. As the straightforward interpretation of this would 
be that UCP3 does not possess uncoupling activity, it may however also indicate that this particular uncoupling protein requires presently unidentified activators. Indeed, Echtay et al. $[112,113]$ initially indicated coenzyme Q as an obligatory factor for uncoupling activity of UCP1, UCP2 and UCP3. Thus, UCP1 expressed in E. coli inclusion bodies did not show the expected fatty-acid dependent reduction of the proton gradient, however, addition of coenzyme Q10 rescued the fatty-acid inducible proton transport to values observed with native UCP1 [112]. In a latter report, similar experiments with similar results were observed for UCP3 [113]. In a subsequent study, Echtay et al. [114] reported that this effect of coenzyme Q10 was actually due to the production of superoxide. Thus, the activation of mitochondrial uncoupling by coenzyme Q10 was abolished when superoxide dismutase was added to the medium, and the replacement of coenzyme Q10 by xanthine plus xanthine oxidase, leading to the formation of superoxide, was similar to coenzyme Q10 able to lower the mitochondrial proton gradient. This superoxide induced mitochondrial uncoupling was dependent on the presence of fatty acids, and was inhibited by nucleotides, and is completely absent in mitochondria isolated from skeletal muscle of UCP3 knock-out mice, indicating that the superoxide-induced mitochondrial uncoupling in muscle is mediated by UCP3 [114].

In the electron transport chain, a small fraction of the electrons 'leak' from the complexes I and III and react with oxygen molecules, leaving superoxide radicals. Superoxide production is thus a natural occuring process that can be considered as an inevitable side-effect of mitochondrial ATP production. An important question is whether UCP3 is also activated by endogenously produced superoxides. To this end, Talbot et al. [115] demonstrated that mitochondria respiring on the complex II substrate succinate produce large amounts of reactive oxygen species and this production can be inhibited by the addition of rotenone, an inhibitor of complex I. This indicates, that the major fractions of electrons under this condition leak from complex I. Next, Talbot et al. [115] showed that skeletal muscle mitochondrial uncoupling was indeed activated by this endogenous superoxide production and could be inhibited by nucleotides. These data suggest that also in 'physiological' conditions, superoxide may be able to activate UCP3.

More details about the mechanisms of superoxide induced mitochondrial uncoupling also came from the group of Brand, who showed that the superoxide-induced activation of UCP3 is mediated via lipid-peroxide intermediates [116]. Thus, reactive oxygen species can interact with polyunsaturated fatty acids, forming reactive aldehydes such as 4-hydroxy-2-nonenal (4HNE). The addition of $4 \mathrm{HNE}$ to mitochondria isolated from skeletal muscle of wild-type mice caused mitochondrial uncoupling that could be inhibited by nucleotides, but the 4HNE-induced lowering of the proton gradient was significantly reduced in UCP3 knock-out mice. At present, the working model for activation of UCP3 by superoxide involves the peroxidation of polyunsaturated fatty acids in the mitochondrial membrane after which the subsequent formed reactive alkenals activate UCP3 and lower the proton gradient across the inner mitochondrial membrane [117].

\subsection{Inhibition of reactive oxygen species production by UCP3}

As mentioned above, ROS are produced by the mitochondria as a side-effect of mitochondrial respiration. In 1996, Skulachev hypothesized that the production of reactive oxygen species by mitochondria is dependent on the proton gradient [118], for which evidence was found later [119]. Thus, lowering of the proton gradient, by mitochondrial uncoupling, results in a reduction of mitochondrial ROS production. As there is a steep relationship between mitochondrial ROS production and proton gradient, 'mild uncoupling' would already reduce mitochondrial ROS production markedly [119]. Supportive for a potential role for UCP3 in regulating such mild uncoupling was the observation that skeletal muscle mitochondria isolated from mice lacking UCP3 produced more superoxide anions in vitro and displayed increased in vivo ROS production when compared to wild-type mice [31]. ROS production in liver, which does not express UCP3 in wild-type animals, was comparable between UCP3 knock-out mice and wild-type mice, indicating that it was indeed the absence of UCP3 in muscle that was responsible for the increased muscular ROS production [31]. Reactive oxygen species are highly reactive and can lead to damage to DNA, RNA, lipids and proteins. In that respect, it has been observed that mice lacking UCP3 have increased levels of oxidative damage to proteins, lipids and DNA [120].

In a recent report, overexpression of UCP3 at physiological levels (2.2-2.5-fold) in L6 muscle cells significantly decreased mitochondrial ROS production [121], although this effect was not due to a UCP3 effect on mitochondrial proton gradient. 
Apart from the observations in genetically manipulated animals, little physiological data that directly linked UCP3 with the production of ROS is available. One study examined the effect of energy restriction, known to increase lifespan in animals, on mitochondrial ROS production and UCP3 protein content. Rats were energy restricted for 12 or 18 months, which decreased mitochondrial ROS production and oxidative damage. The decrease in ROS production was accompanied by an increase in UCP3 protein content [122]. In addition, it has been shown that UCP 3 protein content is reduced by $68 \%$ in 24 -month-old rats compared to young adult rats, and aging is known to be accompanied by (or even be due to) increased oxidative damage, suggesting that the reduction of UCP3 may contribute to the latter [123].

Taken together, there is in vitro evidence that UCP3 can be activated by superoxides and lipid peroxides, and that activation of UCP3 can reduce ROS production. Altogether, this points towards a negative feedback loop between ROS production and subsequent lipid peroxidation on the one hand and mitochondrial uncoupling induced by UCP3 leading to reduction of ROS production on the other hand. However, as deduced from physiological data and expression pattern of UCP3 such a role in ROS production seems to be linked to disturbed fatty acid metabolism.

\section{UCP3 and fatty acid metabolism}

Next to a role in the regulation of ROS production, UCP3 has been consistently related to the metabolism of fatty acids in skeletal muscle. This started with the early finding that UCP3 is rapidly upregulated in the fasted state, which was the earliest observation that made researchers doubt about the role of UCP3 as a true uncoupler. By now there is ample experimental data indicating that UCP3 is closely related to fatty acid metabolism, which will be reviewed below.

\subsection{Physiological conditions showing a positive relationship between UCP3 and fatty acid metabolism}

The fasting induced increase in UCP3 mRNA and protein content is a consistent observation that has been confirmed in many studies $[48,49,124-128]$. Tunstall et al. [127] showed that UCP3 mRNA expression was increased 5-fold after $15 \mathrm{~h}$, and 10-fold after $40 \mathrm{~h}$ of fasting in human skeletal muscle. Remarkably, however, no effect of fasting on the expression of other (PPAR-regulated) genes involved in the uptake, transport, oxidation, and re-esterification of fatty acids was observed in that time frame, suggesting a unique role for UCP3 in the regulation of FA homeostasis during fasting [127]. This is an important finding, as the upregulation of UCP3 by fasting is sometimes simplified as a fatty acid-PPAR effect without physiological meaning. Indeed, as described under Section 3.3.3 (fatty acid and PPAR regulation of UCP3 gene expression) UCP3 is upregulated by high levels of fatty acids and PPAR-agonists. However, the finding by Tunstall et al. [127] suggests that the fasting-induced induction of UCP3 reflects a physiological need for more UCP3 under these circumstances, and is not simply a reflection of increased plasma fatty acid levels. This suggestion is underlined by the finding that abolishing the increase in plasma fatty acids upon fasting via administration of the anti-lipolytic agent nicotinic acid, only prevents upregulation of UCP3 in oxidative muscle, but not in glycolytic muscle [129]. In addition, fasting not only increases UCP3 at the mRNA level, but also at the protein level. It is important to note that it is not self-evident that UCP3 protein levels follow mRNA expression. For example, acute exercise rapidly upregulates UCP3 mRNA [74,78,80,109,110], whereas regular exercise (training) leads to a reduction of UCP3 protein content $[103,104,130]$. Thus upregulation of UCP3 by fasting cannot be reduced to a simple fatty acid/PPAR-effect.

Next to fasting, high-fat feeding also has been shown to result in an upregulation of UCP3 mRNA and protein content, both in rodents [49,68-72] and in humans [73-75]. In addition, the fasting-induced upregulation of UCP3 is rapidly restored upon refeeding a low-fat diet [131], but this restoration of UCP3 is completely absent with high-fat refeeding [71]. Both the fasting- and high-fat induced upregulation of UCP3 is most pronounced in glycolytic compared to oxidative muscle fibers [75,131]. These findings have been interpreted as evidence that UCP3 may play a role in facilitating fat oxidation, as the glycolytic muscle fibers would display a higher capacity to switch from glucose oxidation towards fat oxidation and the fasting and high-fat diet induced upregulation of UCP3 in these muscle fibers could serve to facilitate fat oxidation. 


\subsection{Physiological conditions showing a negative relationship between UCP3 and fatty acid metabolism}

The experiments described above suggest that UCP3 is upregulated under conditions in which plasma fatty acids and fatty acid oxidation are high. Regarding the latter, the observation that UCP3 is highly expressed in type 2b, non-oxidative glycolytic muscle fibers [40] is remarkable. Moreover, UCP3 protein content has been shown to be very low in cardiac muscle, 2-3-fold higher in oxidative muscle (soleus) and 10-fold higher in mixed, glycolytic skeletal muscle [39]. This negative relation between oxidative capacity and UCP3 expression is not easily compatible with a major role of UCP3 in facilitating fatty acid oxidation.

In addition, endurance training, which is accompanied by an increased muscular fatty acid oxidation capacity, leads to a reduction of UCP3 protein content in humans $[103,104,130]$. The reduction of UCP3 protein content has been related to the increase in fatty acid oxidation, with the largest reduction in UCP3 in those subjects [130] or muscle fibers [103] that have the highest fat oxidative capacity. Also weight reduction, known to improve fat oxidative capacity in overweight subjects, is accompanied by a decrease in UCP3 [96,97,132].

With a less physiological, pharmacological approach it was shown that direct inhibition of fatty acid oxidation via the administration of etomoxir, an inhibitor of mitochondrial fatty acid uptake via carnitine-palmitoyl-transferase 1 (CPT1), rapidly upregulates UCP3 mRNA and protein content [133-136]. In addition, patients suffering from riboflavin responsive multiple acylCoA dehydrogenase deficiency (RR-MAD), a rare mitochondrial myopathy, who are characterized by severely hampered fat oxidation, display significant increased levels of UCP3 mRNA and protein content. Treatment of these patients with riboflavin restored fat oxidative capacity to control values accompanied by a return of UCP3 protein levels to control values [137]. Taken together, these data indicate that UCP3 is not positively related to fat oxidative capacity, but rather may be induced under conditions where fat oxidative capacity of the skeletal muscle is low.

Deduced from these data, three hypothesis have been formulated to explain the putative role of UCP3 in fatty acid metabolism, which will be reviewed in the subsequent sections.

\subsection{UCP3 as a mitochondrial exporter of fatty acids when fatty acid oxidation predominates}

The mitochondrial oxidation of fatty acids involves the import of fatty acid into the mitochondrial matrix through CPT1, requiring carnitine as a co-factor. At the cytosolic side, fatty acids are activated by conversion to their CoA-esters. These fatty acyl-CoA esters will diffuse across the outer mitochondrial membrane and reach the inter membrane space. As the inner mitochondrial membrane is impermeable to fatty acyl-CoA, conversion to fatty acyl-carnitine by the action of the enzyme CPT1 facilitates fatty acid transport across the inner mitochondrial membrane. In the mitochondrial matrix, fatty acyl-carnitine is subsequently reconverted to fatty acyl-CoA and carnitine by the action of CPT2, after which it will be subject to $\beta$-oxidation and the resulting acetyl-CoA moieties will enter the TCA cycle. Please note that only fatty acids that are activated by the conjugation to CoA can undergo $\beta$-oxidation. Importantly - at least for long-chain fatty acids - the enzyme that converts fatty acids to fatty acyl-CoA is absent in the mitochondrial matrix and therefore long-chain fatty acids are entirely dependent on the carnitine shuttle to allow their mitochondrial oxidation. Therefore, the carnitine shuttle exists not because fatty acids are unable to enter the mitochondrial matrix, but to channel the fatty acids into the oxidation pathway [138].

Remarkably, inside the mitochondrial matrix acyl-CoA thioesterases have been found [139], whose enzymatic action would hydrolyze fatty acyl-CoA leaving a fatty acid anion and acyl-CoA. Given that the resultant fatty acid cannot be diverted to $\beta$-oxidation, the presence of thioesterases, which liberate fatty acids from their acyl-CoA is counterintuitive. It has been suggested that the physiological function of these thioesterases is the regeneration of mitochondrial supply of CoA for use in other reactions of the TCA cycle and $\beta$-oxidation. According to this suggestion, under conditions of increased mitochondrial entry of fatty acyl-CoA into the mitochondria, the need for $\mathrm{CoA}$ in these reactions exceeds the available $\mathrm{CoA}$ in the matrix, and although removal of CoA from fatty acyl-CoA will reduce the amount of fatty acids that can undergo oxidation, this will have a less dramatic effect on overall fat oxidation than a shortage of CoA in the TCA cycle and $\beta$-oxidation. Thus, thioesterase redistributes the available CoA in the matrix ensuring maintenance of fat oxidation.

A side-effect of thioesterase activity, however, is the release of fatty acids in the matrix, which will be deprotonated due to the proton gradient leaving fatty acid anions inside the mitochondrial matrix. As the 
mitochondrial matrix lacks long chain fatty acyl CoA synthetase, the enzyme that converts long-chain fatty acids to fatty acyl-CoA [140], this fatty acid anion is trapped inside the mitochondrial matrix. Here, Himms-Hagen and Harper [141] hypothesized that UCP3 would facilitate the outward transport of these fatty acid anions from the mitochondrial matrix, consistent with the Skulachev/Garlid/Jezek hypothesis [18-20], to the intermembrane space where the fatty acid anion can be protonated again and leave the intermembrane space. In this way, UCP3 would protect mitochondria against deleterious effects of non-metabolizable fatty acids, and in combination with mitochondrial thioesterase help to enhance fatty acid oxidation by delivering CoA to the TCA cycle and $\beta$-oxidation [141].

In support of the hypothesis of Himms-Hagen, mice overexpressing UCP3 were found to be characterized by increased levels of mitochondrial thioesterase [142]. Another study found that mice lacking the leptin receptor displayed increased levels of both UCP3 and mitochondrial thioesterase in skeletal muscle and both genes were concordantly downregulated by PPAR agonist treatment, suggesting that UCP3 and mitochondrial thioesterase may be involved in the same pathway [143]. Similar results were observed by another research group, showing that fasting and T3 treatment resulted in a concordant upregulation of UCP3 and mitochondrial thioesterase [144]. Although these results can indeed be interpreted as supporting evidence for the Himms-Hagen hypothesis, it cannot be ruled out that the gene expression of UCP3 and mitochondrial thioesterase are simply regulated by similar transcription factors, as has been suggested recently [145].

Bezaire et al. [33] tested this hypothesis in a more direct fashion by examining fatty acid oxidation in mice lacking UCP3, both in the fasting and the fed state. In both conditions, fatty acid oxidation tended to be impaired in UCP3 knock-out mice, although the difference was only significant in the fed state. In a subsequent study [146], it was also shown that mice overexpressing UCP3 in the physiological range (2.3-fold) had significantly higher $24 \mathrm{~h}$ fat oxidation and increases in markers of fatty acid metabolism, such as CPT1, fatty acid binding protein (FAPB) and $\beta$-hydroxyacylCoA dehydrogenase in skeletal muscle. In addition, the amount of lipid in skeletal muscle was reduced too, suggesting that these mice display an increased fat oxidative capacity as would be predicted by their hypothesis. In contrast, however, the same set of fatty acid oxidative markers was found to be unchanged in UCP3 knock-out mice compared to wild-type mice. Finally, in a recent study it was found that overexpression of UCP3 in the physiological range in L6 muscle cells specifically increased palmitate oxidation production and did not affect glucose oxidation [121].

Together, these studies show that overexpression of UCP3 leads to a stimulation of fatty acid oxidation and that a lack of UCP3 may impair fat oxidation. Although these data are consistent with the hypothesis that UCP3 exports fatty acid anions derived from hydrolysis of fatty acylCoA esters by thioesterase action, several findings, described in Section 6.2, are not compatible with the Himms-Hagen hypothesis, and the physiological data to support the hypothesis is limited. In addition, although there is evidence that UCP3 can facilitate fatty acid cycling in the inner mitochondrial membrane. Definite proof that UCP3 can function as an unidirectional exporter of fatty acid anions, however, is still awaited.

\subsection{UCP3 as a mitochondrial exporter of non-metabolizable fatty acids}

At the same time that Himms-Hagen and Harper proposed their hypothesis of UCP3 being a fatty acid anion exporter to facilitate fatty acid oxidation, we postulated the hypothesis that UCP3 may act as a fatty acid anion exporter of fatty acids that entered the mitochondrial matrix via flip-flop and that could therefore not be oxidized (Fig. 4) [130]. As mitochondrial membranes are lipid bilayers they are also permeable for neutral fatty acids. By means of a so-called flip-flop mechanism, fatty acids can diffuse through these membranes, and it has even been suggested that at the cellular level (plasma membrane) this is the major route for fatty acid uptake [138,147]. However, because a proton gradient exists over the inner mitochondrial membrane, fatty acids that flip-flop over this membrane will become deprotonated resulting in fatty acid anions. Importantly, fatty acid anions are not able to flip-flop back across the membrane [148], nor can undergo $\beta$-oxidation because the enzyme that converts long-chain fatty acids to fatty acyl-CoA is absent in the mitochondrial matrix [140]. Therefore, the inner mitochondrial membrane would accumulate fatty acid anions at the side of the mitochondrial matrix. Moreover, these fatty acid anions could potentially leave the inner mitochondrial membrane and accumulate inside the mitochondrial matrix: this could occur either dissolved in the matrix at very low concentrations or bound to the matrix-associated fatty acid binding proteins [149]. In the 


\section{CYTOPLASMA}

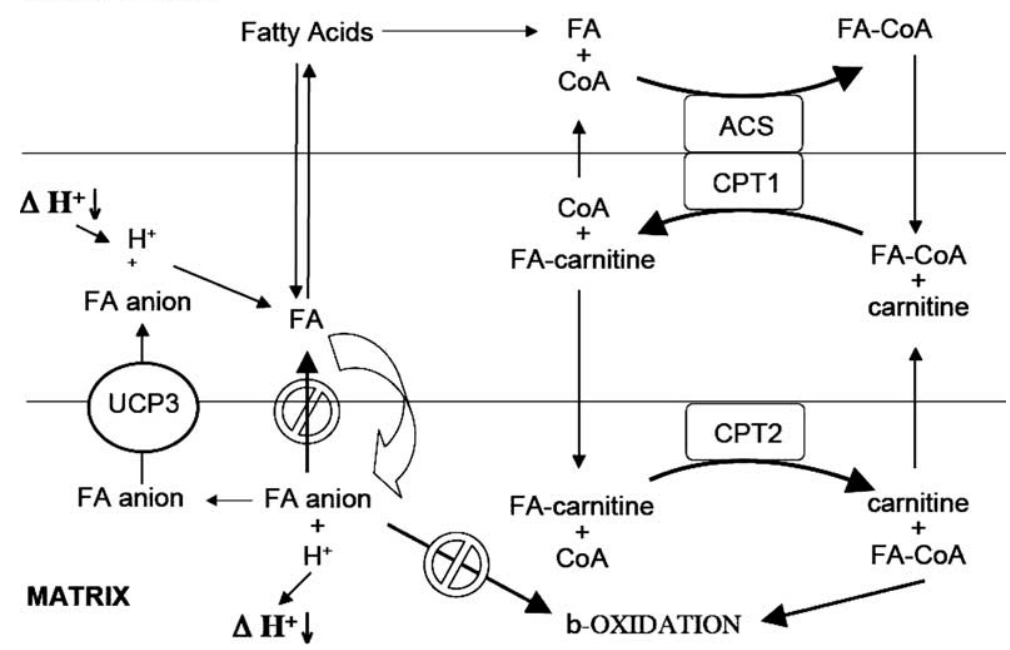

Fig. 4. Schematic model of UCP3's putative function. The normal pathway for fatty acids to enter the mitochondrial matrix is via import through CPT1, requiring carnitine as a co-factor (because the inner mitochondrial membrane is impermeable to fatty acyl-CoA). Please note that only fatty acids that are activated by the conjugation to CoA can undergo $\beta$-oxidation and that - at least for long-chain fatty acids - the enzyme that converts fatty acids to fatty acyl-CoA is absent in the mitochondrial matrix. However, as mitochondrial membranes are lipid bilayers they are also permeable for neutral fatty acids. By means of a so-called flip-flop mechanism, fatty acids can diffuse over these membranes, but because a proton gradient exists over the inner mitochondrial membrane, fatty acids that flip-flop over this membrane will become deprotonated. Importantly, fatty acid anions are not able to flip-flop back across the membrane and therefore the inner mitochondrial membrane would accumulate fatty acid anions at the side of the mitochondrial matrix. In the matrix (or at the inner side of the membrane), these fatty acid anions would be prone to become peroxidized by the reactive oxygen species that are produced in the electron transport chain and which are therefore present in the mitochondrial matrix. UCP3 protects these fatty acid anions against peroxidation by facilitating outward transport. ACS, acyl-CoA synthase.

matrix (or at the inner side of the inner mitochondrial membrane), these fatty acid anions would be prone to become peroxidized by the reactive oxygen species that are produced as an obligatory side product of the electron transport chain and which are therefore present in the mitochondrial matrix. As peroxidized fatty acids are highly reactive [150], they could damage DNA, RNA and proteins of the mitochondrial machinery, which are mainly present in the mitochondrial matrix. Therefore, we postulated that UCP3 may serve as an exporter of non-metabolizable fatty acid anions that entered the mitochondrial matrix via flip-flop, again consistent with the Skulachev/Garlid/Jezek hypothesis [18-20]. At the side of the inner membrane space, the exported fatty acid anions will be protonated again and may either flip-flop back into the matrix (leading to mitochondrial uncoupling via fatty acid cycling), or leave the inner mitochondrial membrane once the cellular fatty acid concentration decreases. This hypothesis was based on observations in physiological studies that UCP3 is upregulated under conditions in which the supply of fatty acids to the muscle exceeds the fat oxidative capacity, such as fasting, high-fat feeding, acute exercise and in type 2b muscle fibers, whereas UCP3 is downregulated when the fat oxidative capacity is high (type 1 muscle fibers, endurance training). Under these conditions where fatty acid supply is mismatched by fatty acid oxidation, fatty acids will accumulate in the cytosol and the chance of fatty acids entering the mitochondrial matrix, and therefore the need for UCP3, will be increased. Therefore, although our hypothesis shows similarities to the Himms-Hagen and Harper hypothesis [141], the major differences are the source of the fatty acid anions and the fact that in our hypothesis UCP3 is not involved in mediating fatty acid oxidation, but merely protects the mitochondria against the deleterious effects of neutral fatty acids.

After we postulated our hypothesis, we performed several experiments that could provide supportive data. First, we used the potential of Etomoxir to inhibit CPT1, the rate-limiting step in the uptake of fatty acyl-CoA in human subjects for $36 \mathrm{~h}$, while consuming a high-fat diet to increase fatty acid supply. According to our hypothesis, this would be one of the most dramatic conditions in which UCP3 is needed, as both the oxidative capacity is low and the supply of fat is high. As anticipated, we indeed found a $67 \%$ induction of UCP3 protein content after $36 \mathrm{~h}$ of Etomoxir treatment, which was related to the Etomoxir-induced 
decrease in fatty acid oxidation [134]. The finding that this short-term intervention led to pronounced changes of UPC 3 at the protein level convinced us that the result was not simply a transcriptional effect of increased fatty acid levels, in fact plasma fatty acid levels were not increased after $36 \mathrm{~h}$ of etomoxir in humans [134]. These findings were confirmed in rats, where we found that Etomoxir treatment for 8 days resulted in a $\sim 2$-fold decrease in CPT1 activity and a $\sim 2$-fold increase in UCP3 [73]. Please note that due to the partial block of CPT1 the fraction of fatty acids entering the mitochondria as their FA CoA esters is limited and hence CoA availability in the matrix will not be limiting. This reduces the need for MTE1 to hydrolyse FA-CoA esters. Thus, according to the Himms-Hagen hypothesis, a block on CPT1 would not result in increased UCP3 content.

In a second study, we used the special characteristics of medium-chain fatty acids to test our hypothesis. An important aspect of our [130] and Himms-Hagen's hypothesis [141] is that neutral fatty acids inside the matrix cannot be oxidized because they can not be converted to fatty-acyl CoAs inside the matrix [151]. However, this is not true for medium-chain fatty acids: these fatty acids can be activated inside the mitochondrial matrix and do not rely on CPT1 for mitochondrial uptake [140,152]. Thus, even when neutral medium-chain fatty acids reach the mitochondrial matrix, they can be activated to fatty acyl$\mathrm{CoA}$ and directed to $\beta$-oxidation [153]. Obviously, these fatty acids do not need to (and should not) be exported from the matrix, eliminating a role for UCP3 in the handling of these specific fatty acids. Thus, there is no need for UCP3 to deal with increased levels of medium chain fatty acids upon consumption of a high fat diet composed of medium chain fatty acids, this in contrast to the anticipated increase on a high fat diet containing predominantly long chain fatty acids. To test this, we fed rats high-fat diets for 14 days, the fat source comprised entirely of either long-chain fatty acids or medium-chain fatty acids, and found that UCP3 protein content was increased 2-fold upon long-chain high-fat feeding, but not affected at all after medium-chain high-fat feeding [39]. This differential response in UCP3 to the two diets was accompanied by a similar rise in plasma free fatty acid levels and could not be explained by a PPAR effect, as other PPAR-responsive genes were similarly affected by the diets [39]. Again these data support our hypothesis that UCP3 is involved in the export of fatty acids that cannot be metabolized from the mitochondrial matrix.

In addition to these studies, the observations that UCP3 protein content (a) is negatively related to fat oxidative capacity [39,40], (b) is decreased by endurance training in relation to the increase in fatty acid oxidation [130], (c) follows changes in fat oxidative capacity in patients suffering from riboflavin responsive multiple acylCoA dehydrogenase deficiency (RR-MAD) before and after riboflavin treatment [137] and (d) is specifically increased in glycolytic muscle fibers upon fasting and high-fat feeding [75,131], all are consistent with the hypothesized role of UCP3 being a fatty acid anion exporter of non-metabolizable fatty acids. In this hypothesis, lack of UCP3 would lead to the accumulation of fatty acid anions in the mitochondrial matrix or at the matrix side of the inner mitochondrial membrane, and these fatty acids would be prone to become peroxidized by reactive oxygen species and could subsequently lead to damage to the mitochondrial machinery. In that context, the finding that mice lacking UCP3 display impaired fatty acid oxidation [33] and have increased levels of oxidative damage to proteins, lipids and DNA [120] is consistent too, although these effects can also be explained by the Himms-Hagen and Harper hypothesis, as by a direct effect of UCP3 on lowering of reactive oxygen species.

Taken together, there are multiple physiological observations that fit the concept of UCP3 being an exporter of fatty acid anions under conditions when not all fatty acids can be oxidized. In contrast to the Himms-Hagen hypothesis, UCP3 would not facilitate fatty acid oxidation, but both hypothesis predict that lack of UCP3 would lead to lipid-induced damage to the mitochondrial machinery. However, definite proof that UCP3 can function as a unidirectional exporter of fatty acid anions is not available to date, but is eagerly awaited.

\subsection{UCP3 as a mitochondrial exporter of lipid peroxides}

In 2003, Goglia and Skulachev [154] proposed a third, closely related hypothesis regarding the physiological role of UCP3 in fatty acid metabolism. According to their hypothesis, UCP3 is involved in the transfer of fatty acid peroxides from the inner to the outer leaflet of the inner mitochondrial membrane, thereby extending the fatty acid cycling hypothesis [154]. In contrast to the previous two hypotheses, this hypothesis was 
based on the observation that UCP3 can act as an antioxidant, as discussed in Section 5. According to Goglia and Skulachev the antioxidant capacity of UCP3 is too prominent to be fully explained by a mild uncoupling effect of UCP3. They assumed that fatty acids at the matrix side of the inner mitochondrial membrane are attacked by reactive oxygen species, resulting in lipid peroxides in the inner leaflet of the inner mitochondrial membrane. These lipid peroxides are expected to be unable to flip-flop to the outer leaflet of the membrane and, as these lipid peroxides are highly reactive, they could lead to major damage to components of the mitochondrial matrix. Goglia and Skulachev, therefore, proposed that UCP3 is involved in the outward translocation of these lipid peroxides. Indeed, UCPs were recently shown to be able to facilitate lipid peroxide cycling [155]. According to the authors, this function of UCP3 would be important as, in contrast to the inter membrane space, oxidative damage to components in the mitochondrial matrix, for example, mtDNA would have deleterious effects on overall mitochondrial function. In that respect, damage to mtDNA has been reversely correlated with longevity in mammals [156]. The importance of reducing oxidative damage in the matrix is also illustrated by the fact that knock-out of the cytosolic superoxide dismutase results in only a mild phenotype, whereas the knock-out of matrix superoxide dismutase results in a neonatal lethal phenotype characterized by mtDNA oxidative damage as well as respiratory chain and Krebs cycle abnormalities [157-159]. In this way, UCP3 has a protective function against oxidative damage that would exceed the effect of UCP3 on mild uncoupling only.

It should be noted that the hypothesis of Goglia and Skulachev [154] only differs slightly from the hypothesis that we initially postulated [130] and recently updated [160]. Whereas our hypothesis was purely based on UCP3 data obtained in physiological studies in which lipid metabolism was manipulated, and on the assumption that UCP3 can export fatty acid anions, Goglia and Skulachev started off from the observation that UCP3 has antioxidant capacity. Importantly, however, the data from most, if not all, physiological studies also perfectly fit with the Goglia and Skulachev hypothesis. The physiological observations, however, do not provide conclusive evidence if UCP3 indeed exports fatty acid anions to prevent mitochondria from peroxidation or actually export the peroxidized fatty acid anions. More importantly, however, both hypotheses predict that UCP3 protects the mitochondrial matrix from the deleterious effects of fatty acids.

\section{Physiological relevance of UCP3: a role in lipotoxicity?}

\subsection{A unifying function for UCP3: protection against lipid-induced oxidative damage}

As reviewed above, there appears consensus that the physiological function of UCP3 is either involved in fatty acid metabolism or in the regulation of the production of reactive oxygen species. Whereas the evidence for a role of UCP3 in the production of reactive oxygen species mainly comes from reconstitution studies and in vitro assays in isolated mitochondria from transgenic animals, the suggestion that UCP3 is involved in fatty acid handling is based on observations in physiological studies, but direct evidence is lacking. It is, however, quite possible that the truth is somewhere in between: UCP3 may be involved in the regulation of ROS production, but specifically under conditions of mitochondrial fat accumulation. In that respect, the finding that 4-hydroxynonenal activates UCP3 [116] provided a plausible link between the two proposed physiological functions: When fatty acid supply to the mitochondria exceeds the oxidative capacity, fatty acids will accumulate in the sarcoplasm. Under these circumstances, the load of fatty acids on the mitochondrial membrane will increase and fatty acids may reach the inner leaflet of the inner mitochondrial membrane. Reactive oxygen species formed in the mitochondrial matrix may attack the fatty acids in the mitochondrial membrane, leading to the formation of lipid peroxides. These peroxides subsequently activate UCP3 leading to a lowering of the proton gradient across the inner mitochondrial membrane, which will subsequently reduce mitochondrial ROS production. Whether in this model UCP3 (a) exports fatty acid anions to prevent them from peroxidation, (b) transports the actual peroxides - both leading to mitochondrial uncoupling via the fatty acid cycling hypothesis and preventing peroxide-induced damage to the mitochondrial machinery- or (c) only directly reduces ROS production by inducting proton transport after activation by lipid-peroxides, should be the topic of further study. However, regardless of the exact mechanism of action of UCP3, the physiological implication of all three hypotheses $[116,130,154]$ is that UCP3 protects the mitochondria against lipid-induced oxidative damage (Fig. 5) [160]. 


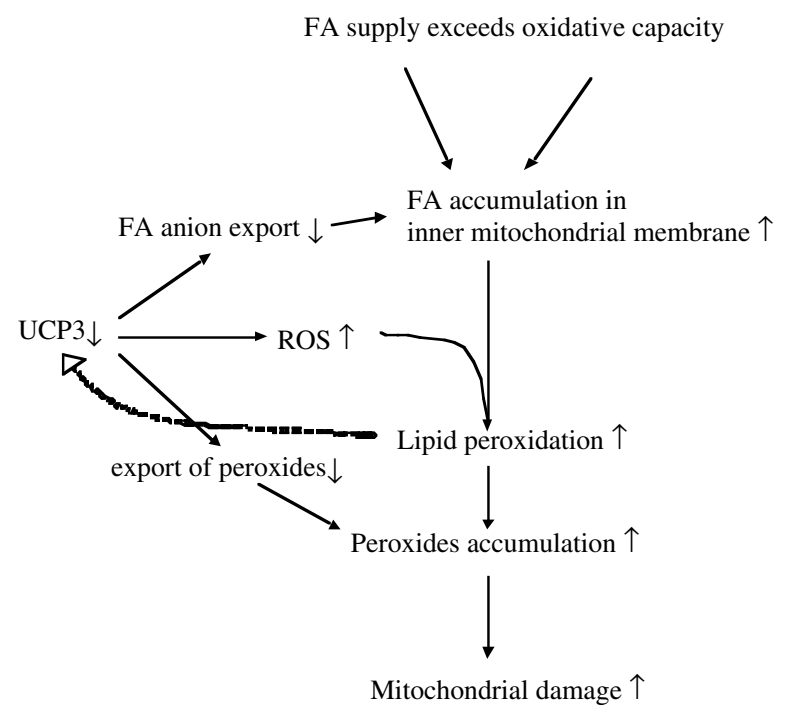

Fig. 5. A unifying mechanism how UCP3 may be involved in the protection against lipid-induce oxidative damage. When fatty acid supply to muscle mitochondria exceeds the oxidative capacity, fatty acids may accumulate in the mitochondrial inner membrane. In the mitochondrial matrix, reactive oxygen species are formed that may attack fatty acids leading to lipid peroxides. As these peroxides are highly reactive, their accumulation could lead to oxidative damage to DNA, RNA and proteins present in the matrix, the side where the mitochondrial machinery is located. UCP3 could protect against this mitochondrial damage by (a) exporting the fatty acid anions from the matrix side of the inner mitochondrial membrane (b) directly lowering ROS production by mild uncoupling or (c) by exporting lipid peroxides from the matrix side of the inner mitochondrial membrane. The effect of reduction of UCP3 is depicted by arrows. The dotted line indicates a negative feedback loop between lipid peroxides and UCP3, in which lipid peroxides are able to activate UCP3. ROS, reactive oxygen species.

\subsection{UCP3, lipotoxicity and type 2 diabetes mellitus}

A putative role for UCP3 in the protection of mitochondria against lipid-induced oxidative damage is well compatible with the upregulation of UCP3 in conditions of mitochondrial fat accumulation. On the other hand, the fact that UCP3 is downregulated when the need for UCP3 is low (because of a high fat oxidative capacity), such as after endurance training [130] or in highly oxidative muscles [39,40], suggests that cells prefer low UCP3 levels. This might be because high levels of UCP3 and the concomitant mild uncoupling may reduce mitochondrial energy efficiency, which could help to understand the early observations of a relationship between UCP3 and energy efficiency (see Section 4). However, low levels of UCP3 that are not compensated for by a high fat oxidative capacity are expected to deteriorate mitochondrial function, for which some evidence is provided by mice lacking UCP3 that display increased levels of oxidative damage to proteins, lipids and DNA [120].

One obvious condition, in which UCP3 may be involved in lipid-induced mitochondrial damage, is type 2 diabetes mellitus. Type 2 diabetic patients are characterized by a reduced fat oxidative capacity [161,162], increased plasma free fatty acid levels $[163,164]$ and increased accumulation of muscular fat $[165,166]$. With these characteristics, increased UCP3 levels would be expected in these patients. However, we have previously found that, at the protein level, UCP3 is reduced by 50\% in type 2 diabetic patients [167]. Recently, we have confirmed this observation by comparing skeletal muscle UCP3 protein content in type 2 diabetic patients, pre-diabetic subjects and healthy controls. We found that UCP3 protein content was reduced by $\sim 40 \%$, in diabetic patients but most important, a similar reduction was already observed in the pre-diabetic state (subjects with impaired glucose tolerane), and these reductions were not due to decreased mitochondrial density. In addition, we found that the decreased levels of UCP3 in type 2 diabetic subjects could be restored by TZD treatment, which improves the diabetic state in these patients [176]. These data suggest that the reduced levels of UCP3 in (pre-) diabetic patients might reflect an unwanted, pathophysiological condition and would predict that these patients have a reduced protection against lipid-induced oxidative mitochondrial damage. In that context, it is very interesting to note that a diminished mitochondrial oxidative capacity and function has 
recently been postulated to be central in the development of type 2 diabetes mellitus $[168,169]$. Thus, insulinresistant subjects and/or type 2 diabetic patients are characterized by elevated levels of 4-hydroxynonenal [170], increased damage to mitochondrial structures [171], have an increased prevalence of mitochondrial DNA damage [172], and display a reduced mitochondrial function [173]. These observations suggest that the reduced levels of UCP3 in the pre-diabetic state may be involved in a reduced protection against lipidinduced oxidative damage to mitochondria, resulting in the deterioration of mitochondrial function as observed in the diabetic state. In that respect, the parallel with aging is interesting, as elderly persons are also characterized by mitochondrial dysfunction [174], accumulation of ROS-induced mutations in control sites of mitochondrial DNA replication [175], and a reduction of UCP3 levels [123].

One argument that could be raised against an important role for UCP3 in the development of type 2 diabetes mellitus is the finding that UCP3 knock-out mice, despite displaying increased levels of oxidative mitochondrial damage [120] do not develop type 2 diabetes. Against this argument, we recently observed that mice lacking UCP3 were indeed characterized by increased levels of lipid peroxidation when fed a low-fat diet, but that on a high-fat diet these mice displayed a remarkable capability of limiting lipid peroxidation by reducing the accumulation of fatty acids in skeletal muscle. Although the mechanism behind this adaptation still deserves in depth investigation, the observation shows that results obtained in UCP3 knock-out mice should be interpreted carefully, and the adaptive capacity to reduce muscular fat levels in $\mathrm{UCP}^{-/-}$mice may well explain why these mice have no apparent phenotype such as obesity and diabetes.

\section{Conclusion}

The discovery of the mitochondrial uncoupling protein-3 was received with great enthusiasm by researchers working in the field of body weight regulation. As with many novel obesity genes discovered in the last decade, the hope was that UCP3 could be a target for future prevention and treatment of overweight and obesity in order to fight the growing prevalence of these disorders. Like the majority of these novel 'obesity' genes, however, hope vanished rapidly when it became evident that UCP3 does not display major uncoupling activity, i.e., is not a major regulator of human energy expenditure. Consistent data gathered over the years shows that UCP3 is closely related to fatty acid metabolism and UCP3 gene expression is rapidly induced by elevated circulating fatty acid levels. The current evidence points towards a function for UCP3 in the regulation of mitochondrial ROS production (deduced from mainly in vitro experiments), or the export of fatty acid anions/peroxides from the matrix-side of the mitochondrial inner membrane (mainly deduced from physiological experiments). So far, definitive (and generally accepted) proof is lacking for all functions of UCP3 and there is urgent need for experiments that combine in vitro experiments with physiological, preferably in vivo studies to establish UCP3's function. Regardless of its exact physiological function, however, the in vivo role of UCP3 seems to be related to the protection of mitochondria against lipid-induced oxidative damage. In that respect, muscular lipotoxicity, linked to the development of type 2 diabetes and among others a direct consequence of increased body fat mass, may be prevented by the induction of UCP3, making this protein a target for the prevention of obesity-induced type 2 diabetes mellitus.

\section{Acknowledgements}

Dr. J. Hoeks was supported by a grant from the Netherlands Organization for Scientific Research (NWO) and the research of Dr. P. Schrauwen has been made possible by a fellowship of the Royal Netherlands Academy of Arts and Sciences (KNAW). Dr. M. Hesselink is supported by a VIDI Research Grant for innovative research from the Netherlands Organization for Scientific Research (NWO).

\section{References}

[1] Mitchell P. Chemiosmotic coupling in oxidative and photosynthetic phosphorylation. Biol Rev Camb Philos Soc 1966;41:445-502.

[2] Boveris A, Oshino N, Chance B. The cellular production of hydrogen peroxide. Biochem J 1972;128:617-30.

[3] Rothwell NJ, Stock MJ. A role for brown adipose tissue in diet-induced thermogenesis. Nature 1979;281:31-5.

[4] Lindberg O, de Pierre J, Rylander E, Afzelius BA. Studies of the mitochondrial energy-transfer system of brown adipose tissue. J Cell Biol 1967;34:293-310. 
[5] Cannon B, Nedergaard J. The biochemistry of an inefficient tissue: brown adipose tissue. Essays Biochem 1985;20:110-64.

[6] Nicholls DG, Locke RM. Thermogenic mechanisms in brown fat. Physiol Rev 1984;64:1-64.

[7] Heaton GM, Wagenvoord RJ, Kemp Jr A, Nicholls DG. Brown-adipose-tissue mitochondria: photoaffinity labelling of the regulatory site of energy dissipation. Eur J Biochem 1978;82:515-21.

[8] Nedergaard J, Golozoubova V, Matthias A, Asadi A, Jacobsson A, Cannon B. UCP1: the only protein able to mediate adaptive non-shivering thermogenesis and metabolic inefficiency. Biochim Biophys Acta 2001;1504:82-106.

[9] Rolfe DFS, Brown GC. Cellular energy utilization and molecular origin of standard metabolic rate in mammals. Physiol Rev 1997;77:731-58.

[10] Fleury C, Neverova M, Collins S, et al. Uncoupling protein-2: a novel gene linked to obesity and hyperinsulinemia. Nat Genet 1997;15:269-73.

[11] Boss O, Samec S, Paoloni-Giacobino A, et al. Uncoupling protein-3: a new member of the mitochondrial carrier family with tissuespecific expression. FEBS Lett 1997;408:39-42.

[12] Chan CB, Saleh MC, Koshkin V, Wheeler MB. Uncoupling protein 2 and islet function. Diabetes 2004;53(Suppl ):S136-42.

[13] Horvath TL, Diano S, Barnstable C. Mitochondrial uncoupling protein 2 in the central nervous system: neuromodulator and neuroprotector. Biochem Pharmacol 2003;65:1917-21.

[14] Paradis E, Clavel S, Bouillaud F, Ricquier D, Richard D. Uncoupling protein 2: a novel player in neuroprotection. Trends Mol Med 2003;9:522-5.

[15] Richard D, Clavel S, Huang Q, Sanchis D, Ricquier D. Uncoupling protein 2 in the brain: distribution and function. Biochem Soc Trans 2001;29:812-7.

[16] Schrauwen P, Hesselink M. UCP2 and UCP3 in muscle controlling body metabolism. J Exp Biol 2002;205:2275-85.

[17] Klingenberg M, Huang SG. Structure and function of the uncoupling protein from brown adipose tissue. Biochim Biophys Acta 1999;1415:271-96.

[18] Garlid KD, Jaburek M, Jezek P. The mechanism of proton transport mediated by mitochondrial uncoupling proteins. FEBS Lett 1998;438:10-4.

[19] Skulachev VP. Fatty acid circuit as a physiological mechanism of uncoupling of oxidative phosphorylation. FEBS Lett 1991;294:158-62.

[20] Jezek P, Orosz DE, Modriansky M, Garlid KD. Transport of anions and protons by the mitochondrial uncoupling protein and its regulation by nucleotides and fatty acids. A new look at old hypotheses. J Biol Chem 1994;269:26184-90.

[21] Nicholls DG. Brown adipose tissue mitochondria. Biochim Biophys Acta 1979;549:1-29.

[22] Jaburek M, Varecha M, Gimeno RE, et al. Transport function and regulation of mitochondrial uncoupling proteins 2 and 3. J Biol Chem 1999;274:26003-7.

[23] Hinz W, Gruninger S, De Pover A, Chiesi M. Properties of the human long and short isoforms of the uncoupling protein-3 expressed in yeast cells. FEBS Lett 1999;462:411-5.

[24] Zhang C-Y, Hagen T, Mootha VK, Slieker LJ, Lowell BB. Assessment of uncoupling activity of uncoupling protein 3 using a yeast heterologous expression system. FEBS Lett 1999;449:129-34.

[25] Heidkaemper D, Winkler E, Muller V, et al. The bulk of UCP3 expressed in yeast cells is incompetent for a nucleotide regulated H+ transport. FEBS Lett 2000;480:265-70.

[26] Winkler E, Heidkaemper D, Klingenberg M, Liu Q, Caskey T. UCP3 expressed in yeast is primarily localized in extramitochondrial particles. Biochem Biophys Res Commun 2001;282:334 40.

[27] Harper JA, Stuart JA, Jekabsons MB, et al. Artifactual uncoupling by uncoupling protein 3 in yeast mitochondria at the concentrations found in mouse and rat skeletal-muscle mitochondria. Biochem J 2002;361:49-56.

[28] Guerini D, Prati E, Desai U, et al. Uncoupling of protein-3 induces an uncontrolled uncoupling of mitochondria after expression in muscle derived L6 cells. Eur J Biochem 2002;269:1373-81.

[29] Clapham JC, Arch JR, Chapman H, et al. Mice overexpressing human uncoupling protein-3 in skeletal muscle are hyperphagic and lean. Nature 2000;406:415-8.

[30] Cadenas S, Echtay KS, Harper JA, et al. The basal proton conductance of skeletal muscle mitochondria from transgenic mice overexpressing or lacking uncoupling protein-3. J Biol Chem 2002;277:2773-8.

[31] Vidal-Puig AJ, Grujic D, Zhang CY, et al. Energy metabolism in uncoupling protein 3 gene knockout mice. J Biol Chem 2000;275:16258-66.

[32] Gong DW, Monemdjou S, Gavrilova O, et al. Lack of obesity and normal response to fasting and thyroid hormone in mice lacking uncoupling protein-3. J Biol Chem 2000;275:16251-7.

[33] Bezaire V, Hofmann W, Kramer JK, Kozak LP, Harper ME. Effects of fasting on muscle mitochondrial energetics and fatty acid metabolism in Ucp3 (-/-) and wild-type mice. Am J Physiol Endocrinol Metab 2001;281:E975-82.

[34] Cline GW, Vidal-Puig AJ, Dufour S, Cadman KS, Lowell BB, Shulman GI. In vivo effects of uncoupling protein-3 gene disruption on mitochondrial energy metabolism. J Biol Chem 2001;276:20240-4.

[35] Solanes G, Vidal-Puig A, Grujic D, Flier JS, Lowell BB. The human uncoupling protein-3 gene: genomic structure, chromosomal localization, and genetic basis for short and long form transcripts. J Biol Chem 1997;272:25433-6.

[36] Esterbauer H, Oberkofler H, Krempler F, Strosberg AD, Patsch W. The uncoupling protein-3 gene is transcribed from tissue-specific promoters in humans but not in rodents. J Biol Chem 2000;275:36394-9.

[37] Gong D-W, He Y, Karas M, Reitman M. Uncoupling protein-3 is a mediator of thermogenesis regulated by thyroid hormone, B3-adrenergic agonists, and leptin. J Biol Chem 1997;272:24129-32. 
[38] Cunningham O, McElligott AM, Carroll AM, et al. Selective detection of UCP 3 expression in skeletal muscle: effect of thyroid status and temperature acclimation. Biochim Biophys Acta 2003;1604:170-9.

[39] Hoeks J, Hesselink MKC, Van Bilsen M, et al. Differential response of UCP3 to medium versus long chain triacylglycerols; manifestation of a functional adaptation. FEBS Lett 2003;555:631-7.

[40] Hesselink MK, Keizer HA, Borghouts LB, et al. Protein expression of UCP3 differs between human type 1, type 2a, and type 2b fibers. FASEB J 2001;15:1071-3.

[41] Acín A, Rodriguez M, Rique H, Canet E, Boutin JA, Galizzi J-P. Cloning and characterization of the $5^{\prime}$ flanking region of the human uncoupling protein 3 (UCP3) gene. Biochem Biophys Res Commun 1999;258:278-83.

[42] Tu N, Chen H, Winnikes U, Reinert I, Pirke KM, Lentes KU. Functional characterization of the $5^{\prime}$-flanking and the promoter region of the human UCP3 (hUCP3) gene. Life Sci 2000;67:2267-79.

[43] Olson EN, Perry M, Schulz RA. Regulation of muscle differentiation by the MEF2 family of MADS box transcription factors. Dev Biol 1995;172:2-14.

[44] Solanes G, Pedraza N, Iglesias R, Giralt M, Villarroya F. Functional relationship between MyoD and peroxisome proliferatoractivated receptor-dependent regulatory pathways in the control of the human uncoupling protein-3 gene transcription. Mol Endocrinol 2003;17:1944-58.

[45] Solanes G, Pedraza N, Iglesias R, Giralt M, Villarroya F. The human uncoupling protein-3 gene promoter requires MyoD and is induced by retinoic acid in muscle cells. FASEB J 2000;14:2141-3.

[46] Boss O, Bobbioni-Harsch E, Assimacopoulos-Jeannet F, et al. Uncoupling protein-3 expression in skeletal muscle and free fatty acids in obesity. Lancet 1998;351:1933.

[47] Khalfallah Y, Fages S, Laville M, Langin D, Vidal H. Regulation of uncoupling protein-2 and uncoupling protein-3 mRNA expression during lipid infusion in human skeletal muscle and subcutaneous adipose tissue. Diabetes 2000;49:25-31.

[48] Millet L, Vidal H, Andreelli F, et al. Increased uncoupling protein-2 and -3 mRNA expression during fasting in obese and lean humans. J Clin Invest 1997;100:2665-70.

[49] Weigle DS, Selfridge LE, Schwartz MW, et al. Elevated free fatty acids induce uncoupling protein 3 expression in muscle. A potential explanation for the effect of fasting. Diabetes 1998;47:298-302.

[50] Solanes G, Pedraza N, Calvo V, Vidal-Puig A, Lowell BB, Villarroya F. Thyroid hormones directly activate the expression of the human and mouse uncoupling protein-3 genes through a thyroid response element in the proximal promoter region. Biochem $\mathbf{J}$ 2005;386:505-13.

[51] Gong DW, He Y, Karas M, Reitman M. Uncoupling protein-3 is a mediator of thermogenesis regulated by thyroid hormone, beta3adrenergic agonists, and leptin. J Biol Chem 1997;272:24129-32.

[52] Lanni A, Moreno M, Lombardi A, Goglia F. Thyroid hormone and uncoupling proteins. FEBS Lett 2003;543:5-10.

[53] Larkin S, Mull E, Miao W, et al. Regulation of the third member of the uncoupling protein family, UCP3, by cold and thyroid hormone. Biochem Biophys Res Commun 1997;240:222-7.

[54] Lombardi A, Silvestri E, Moreno M, et al. Skeletal muscle mitochondrial free-fatty-acid content and membrane potential sensitivity in different thyroid states: involvement of uncoupling protein-3 and adenine nucleotide translocase. FEBS Lett 2002;532:12-6.

[55] de Lange P, Lanni A, Beneduce L, et al. Uncoupling protein-3 is a molecular determinant for the regulation of resting metabolic rate by thyroid hormone. Endocrinology 2001;142:3414-20.

[56] Barbe P, Larrouy D, Boulanger C, et al. Triiodothyronine-mediated up-regulation of UCP2 and UCP3 mRNA expression in human skeletal muscle without coordinated induction of mitochondrial respiratory chain genes. FASEB J 2001;15:13-5.

[57] Jekabsons MB, Gregoire FM, Schonfeld-Warden NA, Warden CH, Horwitz BA. T(3) stimulates resting metabolism and UCP-2 and UCP-3 mRNA but not nonphosphorylating mitochondrial respiration in mice. Am J Physiol 1999;277:E380-9.

[58] Lanni A, Beneduce L, Lombardi A, et al. Expression of uncoupling protein-3 and mitochondrial activity in the transition from hypothyroid to hyperthyroid state in rat skeletal muscle. FEBS Lett 1999;444:250-4.

[59] Jucker BM, Schaeffer TR, Haimbach RE, et al. Reduction of intramyocellular lipid following short-term rosiglitazone treatment in Zucker fatty rats: an in vivo nuclear magnetic resonance study. Metabolism 2003;52:218-25.

[60] Lebon V, Dufour S, Petersen KF, et al. Effect of triiodothyronine on mitochondrial energy coupling in human skeletal muscle. J Clin Invest 2001;108:733-7.

[61] Nagase I, Yoshida T, Saito M. Up-regulation of uncoupling proteins by beta-adrenergic stimulation in L6 myotubes. FEBS Lett 2001;494:175-80.

[62] Savontaus E, Roura J, Boss O, Huupponen R, Koulu M. Differential regulation of uncoupling proteins by chronic treatments with B3-adrenergic agonist BRL 35135 and metformin in obese fa/fa zucker rats. Biochem Biophys Res Commun 1998;246:899-904.

[63] Yoshitomi H, Yamazaki K, Abe S, Tanaka I. Differential regulation of mouse uncoupling proteins among brown adipose tissue, white adipose tissue, and skeletal muscle in chronic beta 3 adrenergic receptor agonist treatment. Biochem Biophys Res Commun 1998;253:85-91.

[64] Nakamura Y, Nagase I, Asano A, et al. Beta 3-adrenergic agonist up-regulates uncoupling proteins 2 and 3 in skeletal muscle of the mouse. J Vet Med Sci 2001;63:309-14.

[65] Hoeks J, van Baak MA, Hesselink MK, et al. Effect of beta1- and beta2-adrenergic stimulation on energy expenditure, substrate oxidation, and UCP3 expression in humans. Am J Physiol Endocrinol Metab 2003;285:E775-82.

[66] Boss O, Samec S, Kühne F, et al. Uncoupling protein-3 expression in rodent skeletal muscle is modulated by food intake but not by changes in environmental temperature. J Biol Chem 1998;273:5-8.

[67] Hwang C-S, Lane MD. Up-regulation of uncoupling protein-3 by fatty acid in C2C12 myotubes. Biochem Biophys Res Commun 1999;258:464-9. 
[68] Brun S, Carmona MC, Mampel T, et al. Uncoupling protein-3 gene expression in skeletal muscle during development is regulated by nutritional factors that alter circulating non-esterified fatty acids. FEBS Lett 1999;453:205-9.

[69] Matsuda J, Hosoda K, Itoh H, et al. Cloning of rat uncoupling protein-3 and uncoupling protein-2 cDNAs: their gene expression in rats fed high-fat diet. FEBS Lett 1997;418:200-4.

[70] Surwit RS, Wang S, Petro AE, et al. Diet-induced changes in uncoupling proteins in obesity-prone and obesity-resistant strains of mice. Proc Natl Acad Sci USA 1998;95:4061-5.

[71] Samec S, Seydoux J, Dulloo AG. Post-starvation gene expression of skeletal muscle uncoupling protein 2 and uncoupling protein 3 in response to dietary fat levels and fatty acid composition. A link with insulin resistance. Diabetes 1999;48:436-41.

[72] Gong D-W, He Y, Reitman ML. Genomic organization and regulation by dietary fat of the uncoupling protein 3 and 2 genes. Biochem Biophys Res Commun 1999;256:27-32.

[73] Schrauwen P, Hoeks J, Schaart G, et al. Uncoupling protein 3 as a mitochondrial fatty acid anion exporter. FASEB J 2003;17:2272-4.

[74] Arkinstall MJ, Tunstall RJ, Cameron-Smith D, Hawley JA. Regulation of metabolic genes in human skeletal muscle by short-term exercise and diet manipulation. Am J Physiol Endocrinol Metab 2004.

[75] Schrauwen P, Hoppeler H, Billeter R, Bakker AH, Pendergast DR. Fiber type dependent upregulation of human skeletal muscle UCP2 and UCP3 mRNA expression by high-fat diet. Int J Obes Relat Metab Disord 2001;25:449-56.

[76] Tsuboyama-Kasaoka N, Tsunoda N, Maruyama K, et al. Up-regulation of uncoupling protein 3 (UCP3) mRNA by exercise training and down-regulation of UCP3 by denervation in skeletal muscles. Biochem Biophys Res Commun 1998;247:498-503.

[77] Cortright RN, Zheng D, Jones JP, et al. Regulation of skeletal muscle UCP-2 and UCP-3 gene expression by exercise and denervation. Am J Physiol Endocrinol Metab 1999;276:E217-21.

[78] Pilegaard H, Ordway GA, Saltin B, Neufer PD. Transcriptional regulation of gene expression in human skeletal muscle during recovery from exercise. Am J Physiol Endocrinol Metab 2000;279:E806-14.

[79] Zhou M, Lin BZ, Coughlin S, Vallega G, Pilch PF. UCP-3 expression in skeletal muscle: effects of exercise, hypoxia, and AMPactivated protein kinase. Am J Physiol Endocrinol Metab 2000;279:E622-9.

[80] Schrauwen P, Hesselink MK, Vaartjes I, et al. Effect of acute exercise on uncoupling protein 3 is a fat metabolism-mediated effect. Am J Physiol Endocrinol Metab 2002;282:E11-7.

[81] Nagase I, Yoshida S, Canas X, et al. Up-regulation of uncoupling protein 3 by thyroid hormone, peroxisome proliferator-activated receptor ligands and 9-cis retinoic acid in L6 myotubes. FEBS Lett 1999;461:319-22.

[82] Son C, Hosoda K, Matsuda J, et al. Up-regulation of uncoupling protein 3 gene expression by fatty acids and agonists for PPARs in L6 myotubes. Endocrinology 2001;142:4189-94.

[83] Brun S, Carmona MC, Mampel T, et al. Activators of peroxisome proliferator-activated receptor-alpha induce the expression of the uncoupling protein-3 gene in skeletal muscle: a potential mechanism for the lipid intake-dependent activation of uncoupling protein3 gene expression at birth. Diabetes 1999;48:1217-22.

[84] Emilsson V, O'Dowd J, Wang S, et al. The effects of rexinoids and rosiglitazone on body weight and uncoupling protein isoform expression in the Zucker fa/fa rat. Metabolism 2000;49:1610-5.

[85] Brunmair B, Gras F, Wagner L, et al. Expression of uncoupling protein-3 mRNA in rat skeletal muscle is acutely stimulated by thiazolidinediones: an exercise-like effect? Diabetologia 2004;47:1611-4.

[86] Bouchard C, Pérusse L, Chagnon YC, Warden G, Ricquier D. Linkage between markers in the vicinity of the uncoupling protein 2 gene and resting metabolic rate in humans. Hum Mol Genet 1997;6:1887-9.

[87] Walder K, Norman RA, Hanson RL, et al. Association between uncoupling protein polymorphisms (UCP2-UCP3) and energy metabolism/obesity in Pima indians. Hum Mol Genet 1998;7:1431-5.

[88] Astrup A, Toubro S, Dalgaard LT, Urhammer SA, Sørensen TIA, Pedersen O. Impact of the v/v 55 polymorphism of the uncoupling protein 2 gene on 24-h energy expenditure and substrate oxidation. Int J Obes Relat Metab Disord 1999;23:1030-4.

[89] Buemann B, Schierning B, Toubro S, et al. The association between the val/ala-55 polymorphism of the uncoupling protein 2 gene and exercise efficiency. Int J Obes Relat Metab Disord 2001;25:467-71.

[90] Ukkola O, Tremblay A, Sun G, Chagnon YC, Bouchard C. Genetic variation at the uncoupling protein 1, 2 and 3 loci and the response to long-term overfeeding. Eur J Clin Nutr 2001;55:1008-15.

[91] Kimm SY, Glynn NW, Aston CE, et al. Racial differences in the relation between uncoupling protein genes and resting energy expenditure. Am J Clin Nutr 2002;75:714-9.

[92] Lentes K-U, Tu N, Chen H, et al. Genomic organization and mutational analysis of the human UCP2 gene, a prime candidate gene for human obesity. J Recept Signal Transduct Res 1999;19:229-44.

[93] Klannemark M, Orho M, Groop L. No relationship between identified variants in the uncoupling protein 2 gene and energy expenditure. Eur J Endocrinol 1998;139:217-23.

[94] Yanovski JA, Diament AL, Sovik KN, et al. Associations between uncoupling protein 2, body composition, and resting energy expenditure in lean and obese African American, white, and Asian children. Am J Clin Nutr 2000;71:1405-20.

[95] Schrauwen P, Xia J, Bogardus C, Pratley RE, Ravussin E. Skeletal muscle uncoupling protein 3 expression is a determinant of energy expenditure in Pima Indians. Diabetes 1999;48:146-9.

[96] Schrauwen P, Schaart G, Saris WH, et al. The effect of weight reduction on skeletal muscle UCP2 and UCP3 mRNA expression and UCP3 protein content in Type II diabetic subjects. Diabetologia 2000;43:1408-16.

[97] Vidal-Puig A, Rosenbaum M, Considine RC, Leibel RL, Dohm GL, Lowell BB. Effects of obesity and stable weight reduction on UCP2 and UCP3 gene expression in humans. Obes Res 1999;7:133-40. 
[98] Simonyan RA, Jimenez M, Ceddia RB, Giacobino JP, Muzzin P, Skulachev VP. Cold-induced changes in the energy coupling and the UCP3 level in rodent skeletal muscles. Biochim Biophys Acta 2001;1505:271-9.

[99] Schrauwen P, Westerterp-Plantenga MS, Kornips E, Schaart G, van Marken Lichtenbelt WD. The effect of mild cold exposure on UCP3 mRNA expression and UCP3 protein content in humans. Int J Obes Relat Metab Disord 2002;26:450-7.

[100] Golozoubova V, Hohtola E, Matthias A, Jacobsson A, Cannon B, Nedergaard J. Only UCP1 can mediate adaptive nonshivering thermogenesis in the cold. FASEB J 2001. doi:10.1096/fj.00-0536fje.

[101] Schrauwen P, Troost FJ, Xia J, Ravussin E, Saris WH. Skeletal muscle UCP2 and UCP3 expression in trained and untrained male subjects. Int J Obes Relat Metab Disord 1999;23:966-72.

[102] Russell A, Wadley G, Snow R, et al. Slow component of [V]O(2) kinetics: the effect of training status, fibre type, UCP3 mRNA and citrate synthase activity. Int J Obes Relat Metab Disord 2002;26:157-64.

[103] Russell AP, Somm E, Praz M, et al. UCP3 protein regulation in human skeletal muscle fibre types I, IIa and IIx is dependent on exercise intensity. J Physiol 2003;550:855-61.

[104] Schrauwen P, Russell AP, Moonen-Kornips E, Boon N, Hesselink MK. Effect of 2 weeks of endurance training on uncoupling protein 3 content in untrained human subjects. Acta Physiol Scand 2005;183:273-80.

[105] Boss O, Samec S, Desplanches D, et al. Effect of endurance training on mRNA expression of uncoupling proteins 1,2 and 3 in the rat. FASEB J 1998;12:335-9.

[106] Jones TE, Baar K, Ojuka E, Chen M, Holloszy JO. Exercise induces an increase in muscle UCP3 as a component of the increase in mitochondrial biogenesis. Am J Physiol Endocrinol Metab 2003;284:E96-E101.

[107] Putman CT, Dixon WT, Pearcey JA, et al. Chronic low-frequency stimulation upregulates uncoupling protein-3 in transforming rat fast-twitch skeletal muscle. Am J Physiol Regul Integr Comp Physiol 2004;287:R1419-26.

[108] Ljubicic V, Adhihetty PJ, Hood DA. Role of UCP3 in state 4 respiration during contractile activity-induced mitochondrial biogenesis. J Appl Physiol 2004;97:976-83.

[109] Hildebrandt AL, Neufer PD. Exercise attenuates the fasting-induced transcriptional activation of metabolic genes in skeletal muscle. Am J Physiol Endocrinol Metab 2000;278:E1078-86.

[110] Noland RC, Hickner RC, Jimenez-Linan M, et al. Acute endurance exercise increases skeletal muscle uncoupling protein-3 gene expression in untrained but not trained humans. Metabolism 2003;52:152-8.

[111] Pedersen SB, Lund S, Buhl ES, Richelsen B. Insulin and contraction directly stimulate UCP2 and UCP3 mRNA expression in rat skeletal muscle in vitro. Biochem Biophys Res Commun 2001;283:19-25.

[112] Echtay KS, Winkler E, Klingenberg M. Coenzyme Q is an obligatory cofactor for uncoupling protein function. Nature 2000;408:609-13.

[113] Echtay KS, Winkler E, Frischmuth K, Klingenberg M. Uncoupling proteins 2 and 3 are highly active H(+) transporters and highly nucleotide sensitive when activated by coenzyme Q (ubiquinone). Proc Natl Acad Sci USA 2001;98:1416-21.

[114] Echtay KS, Roussel D, St-Pierre J, et al. Superoxide activates mitochondrial uncoupling proteins. Nature 2002;415:96-9.

[115] Talbot DA, Lambert AJ, Brand MD. Production of endogenous matrix superoxide from mitochondrial complex I leads to activation of uncoupling protein 3. FEBS Lett 2004;556:111-5.

[116] Echtay KS, Esteves TC, Pakay JL, et al. A signalling role for 4-hydroxy-2-nonenal in regulation of mitochondrial uncoupling. EMBO J 2003;22:4103-10.

[117] Brand MD, Affourtit C, Esteves TC, et al. Mitochondrial superoxide: production, biological effects, and activation of uncoupling proteins. Free Radic Biol Med 2004;37:755-67.

[118] Skulachev VP. Role of uncoupled and non-coupled oxidations in maintenance of safely low levels of oxygen and its one-electron reductants. Q Rev Biophys 1996;29:169-202.

[119] Korshunov SS, Skulachev VP, Starkov AA. High protonic potential actuates a mechanism of production of reactive oxygen species in mitochondria. FEBS Lett 1997;416:15-8.

[120] Brand MD, Pamplona R, Portero-Otin M, et al. Oxidative damage and phospholipid fatty acyl composition in skeletal muscle mitochondria from mice underexpressing or overexpressing uncoupling protein 3. Biochem J 2002;368:597-603.

[121] MacLellan JD, Gerrits MD, Gowing A, Smith PJS, Wheeler MB, Harper ME. Physiological increases in uncoupling protein 3 augment fatty acid oxidation and decrease reactive oxygen species production without uncoupling respiration in muscle cells. Diabetes 2005;54:2343-50.

[122] Bevilacqua L, Ramsey JJ, Hagopian K, Weindruch R, Harper ME. Long-term caloric restriction increases UCP3 content but decreases proton leak and reactive oxygen species production in rat skeletal muscle mitochondria. Am J Physiol Endocrinol Metab 2005.

[123] Kerner J, Turkaly PJ, Minkler PE, Hoppel CL. Aging skeletal muscle mitochondria in the rat: decreased uncoupling protein-3 content. Am J Physiol Endocrinol Metab 2001;281:E1054-62.

[124] Jimenez M, Yvon C, Lehr L, et al. Expression of uncoupling protein-3 in subsarcolemmal and intermyofibrillar mitochondria of various mouse muscle types and its modulation by fasting. Eur J Biochem 2002;269:2878-84.

[125] Cadenas S, Buckingham JA, Samec S, et al. UCP2 and UCP3 rise in starved rat skeletal muscle but mitochondrial proton conductance is unchanged. FEBS Lett 1999;462:257-60.

[126] Sivitz WI, Fink BD, Donohoue PA. Fasting and leptin modulate adipose and muscle uncoupling protein: divergent effects between messenger ribonucleic acid and protein expression. Endocrinology 1999;140:1511-9.

[127] Tunstall RJ, Mehan KA, Hargreaves M, Spriet LL, Cameron-Smith D. Fasting activates the gene expression of UCP3 independent of genes necessary for lipid transport and oxidation in skeletal muscle. Biochem Biophys Res Commun 2002;294:301-8.

[128] Iossa S, Lionetti L, Mollica MP, et al. Differences in proton leak kinetics, but not in UCP3 protein content, in subsarcolemmal and intermyofibrillar skeletal muscle mitochondria from fed and fasted rats. FEBS Lett 2001;505:53-6. 
[129] Samec S, Seydoux J, Dulloo AG. Interorgan signaling between adipose tissue metabolism and skeletal muscle uncoupling protein homologs: is there a role for circulating free fatty acids? Diabetes 1998;47:1693-8.

[130] Schrauwen P, Saris WH, Hesselink MK. An alternative function for human uncoupling protein 3: protection of mitochondria against accumulation of nonesterified fatty acids inside the mitochondrial matrix. FASEB J 2001;15:2497-502.

[131] Samec S, Seydoux J, Dulloo AG. Role of UCP homologues in skeletal muscles and brown adipose tissue: mediators of thermogenesis or regulators of lipids as fuel substrate? FASEB J 1998;12:715-24.

[132] Mingrone G, Rosa G, Greco AV, et al. Decreased uncoupling protein expression and intramyocytic triglyceride depletion in formerly obese subjects. Obes Res 2003;11:632-40.

[133] Samec S, Seydoux J, Dulloo AG. Skeletal muscle UCP3 and UCP2 gene expression in response to inhibition of free fatty acid flux through mitochondrial beta-oxidation. Pflugers Arch 1999;438:452-7.

[134] Schrauwen P, Hinderling V, Hesselink MKC, et al. Etomoxir-induced increase in UCP3 supports a role of uncoupling protein 3 as a mitochondrial fatty acid anion exporter. FASEB J 2002;16. doi:10.1096/fj.02-0275fje.

[135] Cabrero A, Alegret M, Sanchez R, Adzet T, Laguna JC, Vazquez M. Etomoxir, sodium 2-[6-(4-chlorophenoxy)hexyl]oxirane-2carboxylate, up-regulates uncoupling protein-3 mRNA levels in primary culture of rat preadipocytes. Biochem Biophys Res Commun 1999;263:87-93.

[136] Cabrero A, Alegret M, Sanchez R, Adzet T, Laguna JC, Vazquez M. Uncoupling protein-3 mRNA up-regulation in C2C12 myotubes after etomoxir treatment. Biochim Biophys Acta 2001;1532:195-202.

[137] Russell AP, Schrauwen P, Somm E, et al. Decreased fatty acid $\beta$-oxidation in riboflavin-responsive multiple acylCoA dehydrogenase deficient patients is associated with an increase in UCP3. J Clin Endocrinol Metab 2003;88:5921-6.

[138] Hamilton JA. Fatty acid transport: difficult or easy? J Lipid Res 1998;39:467-81.

[139] Svensson LT, Engberg ST, Aoyama T, Usuda N, Alexson SE, Hashimoto T. Molecular cloning and characterization of a mitochondrial peroxisome proliferator-induced acyl-CoA thioesterase from rat liver. Biochem J 1998;329(Pt 3):601-8.

[140] Tol VA. Aspects of long-chain acyl-COA metabolism. Mol Cell Biochem 1975;7:19-31.

[141] Himms-Hagen J, Harper ME. Physiological role of UCP3 may be export of fatty acids from mitochondria when fatty acid oxidation predominates: an hypothesis. Exp Biol Med (Maywood) 2001;226:78-84.

[142] Moore GB, Himms-Hagen J, Harper ME, Clapham JC. Overexpression of UCP-3 in skeletal muscle of mice results in increased expression of mitochondrial thioesterase mRNA. Biochem Biophys Res Commun 2001;283:785-90.

[143] Clapham JC, Coulthard VH, Moore GB. Concordant mRNA expression of UCP-3, but not UCP-2, with mitochondrial thioesterase- 1 in brown adipose tissue and skeletal muscle in db/db diabetic mice. Biochem Biophys Res Commun 2001;287:1058-62.

[144] Moreno M, Lombardi A, De Lange P, et al. Fasting, lipid metabolism, and triiodothyronine in rat gastrocnemius muscle: interrelated roles of uncoupling protein 3, mitochondrial thioesterase, and coenzyme Q. FASEB J 2003;17:1112-4.

[145] Stavinoha MW, Soloway RD. Current therapy of chronic liver disease. Drugs 1990;39:814-40.

[146] Bezaire V, Spriet LL, Campbell S, et al. Constitutive UCP3 overexpression at physiological levels increases mouse skeletal muscle capacity for fatty acid transport and oxidation. FASEB J 2005;19:977-9.

[147] Hamilton JA, Kamp F. How are free fatty acids transported in membranes? Is it by proteins or by free diffusion through the lipids? Diabetes 1999;48:2255-69.

[148] Ho JK, Duclos Jr RI, Hamilton JA. Interactions of acyl carnitines with model membranes: a (13)C-NMR study. J Lipid Res 2002;43:1429-39.

[149] Unterberg C, Borchers T, Hojrup P, Roepstorff P, Knudsen J, Spener F. Cardiac fatty acid-binding proteins. Isolation and characterization of the mitochondrial fatty acid-binding protein and its structural relationship with the cytosolic isoforms. $\mathrm{J}$ Biol Chem 1990;265:16255-61.

[150] Yagi K. Lipid peroxides and human diseases. Chem Phys Lipid 1987;45:337-51.

[151] Kerner J, Hoppel C. Fatty acid import into mitochondria. Biochim Biophys Acta 2000;1486:1-17.

[152] Rasmussen BB, Holmback UC, Volpi E, Morio-Liondore B, Paddon-Jones D, Wolfe RR. Malonyl coenzyme A and the regulation of functional carnitine palmitoyltransferase-1 activity and fat oxidation in human skeletal muscle. J Clin Invest 2002;110:1687-93.

[153] Fujino T, Takei YA, Sone H, et al. Molecular identification and characterization of two medium-chain acyl-CoA synthetases, MACS1 and the Sa gene product. J Biol Chem 2001;276:35961-6.

[154] Goglia F, Skulachev VP. A function for novel uncoupling proteins: antioxidant defense of mitochondrial matrix by translocating fatty acid peroxides from the inner to the outer membrane leaflet. FASEB J 2003;17:1585-91.

[155] Jaburek M, Miyamoto S, Di Mascio P, Garlid KD, Jezek P. Hydroperoxy fatty acid cycling mediated by mitochondrial uncoupling protein UCP2. J Biol Chem 2004;279:53097-102.

[156] Barja G. Rate of generation of oxidative stress-related damage and animal longevity. Free Radic Biol Med 2002;33:1167-72.

[157] Carlsson LM, Jonsson J, Edlund T, Marklund SL. Mice lacking extracellular superoxide dismutase are more sensitive to hyperoxia. Proc Natl Acad Sci USA 1995;92:6264-8.

[158] Melov S, Ravenscroft J, Malik S, et al. Extension of life-span with superoxide dismutase/catalase mimetics. Science 2000;289:1567-9.

[159] Reaume AG, Elliott JL, Hoffman EK, et al. Motor neurons in $\mathrm{Cu} / \mathrm{Zn}$ superoxide dismutase-deficient mice develop normally but exhibit enhanced cell death after axonal injury. Nat Genet 1996;13:43-7.

[160] Schrauwen P, Hesselink MK. Oxidative capacity, lipotoxicity, and mitochondrial damage in type 2 diabetes. Diabetes 2004;53:1412-7.

[161] Kelley DE, Simoneau J-A. Impaired free fatty acid utilization by skeletal muscle in non-insulin dependent diabetes mellitus. J Clin Invest 1994;94:2349-56. 
[162] Blaak EE, Wagenmakers AJ, Glatz JF, et al. Plasma FFA utilization and fatty acid-binding protein content are diminished in type 2 diabetic muscle. Am J Physiol Endocrinol Metab 2000;279:E146-54.

[163] Schalch DS, Kipnis DM. Abnormalities in carbohydrate tolerance associated with elevated plasma nonesterified fatty acids. J Clin Invest 1965;44:2010-20.

[164] McGarry JD. Banting lecture 2001: dysregulation of fatty acid metabolism in the etiology of type 2 diabetes. Diabetes 2002;51:7-18.

[165] Perseghin G, Scifo P, De Cobelli F, et al. Intramyocellular triglyceride content is a determinant of in vivo insulin resistance in humans: a 1H-13C nuclear magnetic resonance spectroscopy assessment in offspring of type 2 diabetic parents. Diabetes 1999;48:1600-6.

[166] Krssak M, Falk Petersen K, Dresner A, et al. Intramyocellular lipid concentrations are correlated with insulin sensitivity in humans: a 1H NMR spectroscopy study. Diabetologia 1999;42:113-6.

[167] Schrauwen P, Hesselink MK, Blaak EE, et al. Uncoupling protein 3 content is decreased in skeletal muscle of patients with type 2 diabetes. Diabetes 2001;50:2870-3.

[168] Mootha VK, Lindgren CM, Eriksson KF, et al. PGC-1alpha-responsive genes involved in oxidative phosphorylation are coordinately downregulated in human diabetes. Nat Genet 2003;34:267-73.

[169] Patti ME, Butte AJ, Crunkhorn S, et al. Coordinated reduction of genes of oxidative metabolism in humans with insulin resistance and diabetes: potential role of PGC1 and NRF1. Proc Natl Acad Sci USA 2003;100:8466-71.

[170] Russell AP, Gastaldi G, Bobbioni-Harsch E, et al. Lipid peroxidation in skeletal muscle of obese as compared to endurance-trained humans: a case of good vs. bad lipids? FEBS Lett 2003;551:104-6.

[171] Kelley DE, He J, Menshikova EV, Ritov VB. Dysfunction of mitochondria in human skeletal muscle in type 2 diabetes. Diabetes 2002;51:2944-50.

[172] Liang P, Hughes V, Fukagawa NK. Increased prevalence of mitochondrial DNA deletions in skeletal muscle of older individuals with impaired glucose tolerance: possible marker of glycemic stress. Diabetes 1997;46:920-3.

[173] Petersen KF, Dufour S, Befroy D, Garcia R, Shulman GI. Impaired mitochondrial activity in the insulin-resistant offspring of patients with type 2 diabetes. N Engl J Med 2004;350:664-71.

[174] Petersen KF, Befroy D, Dufour S, et al. Mitochondrial dysfunction in the elderly: possible role in insulin resistance. Science 2003;300:1140-2.

[175] Michikawa Y, Mazzucchelli F, Bresolin N, Scarlato G, Attardi G. Aging-dependent large accumulation of point mutations in the human mtDNA control region for replication. Science 1999;286:774-9.

[176] Schrauwen P, Mensink M, Schaart G, Moonen-Kornips E, Sels J-P, Blaak EE, et al. Reduced skeletal muscle UCP3 protein content in pre-diabetic subjects and type 2 diabetic patients: restoration by rosiglitazone treatment. J Clin Endocrinol Metab [in press]. 